\title{
Proposing Several Model Techniques Including ANN and M5P-tree to Forecast the Stress at the Failure of Geopolymer Concrete Mixtures Incorporated Nano- silica
}

Hemn Unis Ahmed ( $\nabla$ hemn.ahmed@univsul.edu.iq)

University of Sulaimani https://orcid.org/0000-0003-2391-4895

Ahmed S. Mohammed

University of Sulaimani

Azad A. Mohammed

University of Sulaimani

\section{Research Article}

Keywords: Geopolymer concrete, Mix proportion, Nano-silica, Compressive strength, Modeling, Sensitivity

Posted Date: January 14th, 2022

DOI: https://doi.org/10.21203/rs.3.rs-1146668/v1

License: @ (i) This work is licensed under a Creative Commons Attribution 4.0 International License. Read Full License 


\section{Abstract}

Geopolymers are innovative cementitious materials that can completely replace traditional Portland cement composites and have a lower carbon footprint than Portland cement. Recent efforts have been made to incorporate various nanomaterials, most notably nano-silica (nS), into geopolymer concrete (GPC) to improve the composite's properties and performance. Compression strength (CS) is one of the essential properties of all types of concrete composites, including geopolymer concrete. As a result, creating a credible model for forecasting concrete CS is critical for saving time, energy, and money, as well as providing guidance for scheduling the construction process and removing formworks. This paper presents a large amount of mixed design data correlated to mechanical strength using empirical correlations and neural networks. Several models, including artificial neural network, M5P-tree, linear regression, nonlinear regression, and multilogistic regression models were utilized to create models for forecasting the CS of GPC incorporated nS. In this case, about 207 tested CS values were collected from literature studies and then analyzed to promote the models. For the first time, eleven effective variables were employed as input model parameters during the modeling process, including the alkaline solution to binder ratio, binder content, fine and coarse aggregate content, $\mathrm{NaOH}$ and $\mathrm{Na}_{2} \mathrm{SiO}_{3}$ content, $\mathrm{Na}_{2} \mathrm{SiO}_{3} / \mathrm{NaOH}$ ratio, molarity, $\mathrm{nS}$ content, curing temperatures, and ages. The developed models were assessed using different statistical tools such as RMSE, MAE, SI, OBJ value, and $\mathrm{R}^{2}$. Results revealed that the ANN model estimated the CS of GPC incorporated nS more accurately than the other models. On the other hand, the alkaline solution to binder ratio, molarity, $\mathrm{NaOH}$ content, curing temperature, and ages were those parameters that have significant influences on the CS of GPC incorporated nS.

\section{Introduction}

The most frequently used construction material is concrete (Abdullah et al., 2021). Yet, Portland cement is the primary cementing material used to bind the ingredients of the concrete composites. However, producing Portland cement necessitates a significant quantity of energy and raw materials, which creates a large amount of total carbon dioxide (about 7\%) into the atmosphere (Mahasenan et al., 2003). However, cement-based concrete remains the most widely

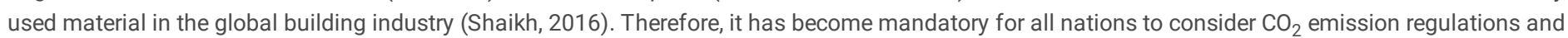
reductions (Yildirim et al., 2014). As a result, extensive research has been conducted to develop a new material that can be used as an alternative to Portland cement (Provis et al., 2015); among them, geopolymer technology was developed in France by professor Davidovits (Abdel-Gawwad and Abo-El-Enein, 2016). Due to the high consumption of waste materials in mixed proportions, GPC emits approximately $70 \%$ less green gas than conventional concrete (Weil et al., 2009).

Geopolymers are an inorganic alumino-silicate polymer family produced through alkaline activation of various aluminosilicate virgin or waste materials rich in silicon and aluminum (Davidovits, 2015). The mixed proportions of the GPC consist of aluminosilicate source binder materials, fine and coarse aggregates, alkaline solutions, and water. The polymerization between the alkaline solutions and source binder materials produces solid concrete, almost like traditional concrete composites (Omer et al., 2015). Many factors influenced on the properties and performances of GPC, including the molarity of $\mathrm{NaOH}$, the ratio of $\mathrm{Na}_{2} \mathrm{SiO}_{3} / \mathrm{NaOH}$, curing regime and ages, water to solids ratio, alkaline solution to binder ratio, elemental composition and type of source binder materials, ratio of $\mathrm{Si}$ to $\mathrm{Al}$ in the geopolymer system, mixing time and rest period, superplasticizer dosage and extra water contents, and coarse and fine aggregate contents (Mohammed et al., 2021).

Nanotechnology is the ability to monitor and restructure matter at the atomic and molecular levels in the range of 1 to $100 \mathrm{~nm}$, as well as the contribution to the distinct properties and phenomena at that size that are equivalent to those associated with individual atoms and molecules or bulk behavior (Roco et al., 2000). Nanotechnology is a burgeoning field of research, with novel science and practical applications gradually gaining prominence over the last two decades. Recently, efforts have been made to incorporate nanoparticles (NPs) into construction materials to improve the properties and performance of concrete (Lazaro et al., 2016). NPs were introduced with geopolymer matrices to enhance durability issues, physical structure, and mechanical properties of the geopolymer mixture (Assaedi et al., 2016). Because NPs have a higher surface area to volume ratio, they are highly reactive and have an effect on reaction rates (Wiesner and Bottero, 2017). As a result, NPs modifies the microstructure of GPC at the atomic level, resulting in significant improvements in both the fresh and hardened states, as well as microstructural behavior of geopolymer composites (Adak et al., 2017). In the literature, a wide range of NPs like nanosilica (nS) (Mustakim et al., 2020), nano-clay (nC) (Ravitheja and Kumar, 2019), nano-alumina (nA) (Shahrajabian and Behfarnia, 2018), carbon nanotubes (CNT) (Kotop et al., 2021), nano-metakaolin (Nm) (Rabiaa et al., 2020), nano-titanium (nT) (Sastry et al., 2021) were consumed to improve various properties of the geopolymer composites, with nS being the most frequent as shown in Table 1. Since nano-silica was the most used material among all types of NPs, this study was devoted to proposing different models to estimate the CS of GPC composites incorporated nS.

Compression strength is a critical characteristic of all concrete composites, including GPC. The CS provides a broad assessment of the quality of the concrete (Ahmed et al., 2021a). However, the concrete's CS at 28 days is critical in structural design and construction. As a result, creating a credible model for estimating the CS of concrete is crucial in terms of modifying or validating the concrete mix proportions (Golafshani et al., 2020). Several factors influence the CS of GPC, resulting in a wide range of compression strength results; consequently, estimating CS is a problematic issue for scholars and engineers. As a result, new numerical and mathematical models are required to clarify this issue (Shahmansouri et al., 2020a). Machine learning methods have been utilized in the literature to model various features of concretes, such as the CS of green concrete (Velay-Lizancos et al., 2017), essential mechanical properties of recycled concrete aggregate (Gholampour et al., 2020), recycled concrete aggregate modulus of elasticity (Golafshani and Behnood, 2018), the CS of environmentally friendly GPC using natural zeolite and silica-fume (Shahmansouri et al., 2020b), the CS of nS-modified self-compacting concrete (Faraj et al., 2021), the CS of fly ash-based GPC composites (Ahmed et al., 2021b), and so on.

In the literature, there is a shortage of studies examining the impact of different mixture proportion parameters on the CS of GPC incorporated nS at various curing temperatures and ages. Also, according to a complete and systematic assessment of GPC, the construction industry rarely uses an authoritative and developed model that uses numerous parameters to estimate the CS of GPC incorporated nS. Most efforts have focused on a single-scale model that does not account for a wide range of experimental data or factors. Moreover, the CS of GPC is influenced by several factors. As a result, in a single equation and model 
structure, the effects of eleven variables such as the alkaline solution to binder ratio (l/b), binder content (b), fine (FA) and coarse (CA) aggregate content, sodium hydroxide (SH) and sodium silicate (SS) content, the ratio of SS/SH, the molarity of SH (M), nS content, curing temperatures (T), and ages (A) were considered and quantified on the CS of GPC incorporated nS by using different model techniques, namely artificial neural network (ANN), M5P-tree (M5P), linear regression (LR), nonlinear regression (NLR), and multi logistic (MLR) models. Finally, different statistical tools, such as the root mean squared error (RMSE), mean absolute error (MAE), scatter index ( $\mathrm{SI}), \mathrm{OBJ}$ value, and the coefficient of determination $\left(\mathrm{R}^{2}\right)$, were used to evaluate the created models' accuracy.

\section{Research Significance}

The primary goal of this paper is to create multiscale models for estimating the CS of GPC incorporated nS. Thus, a diverse range of laboratory work data, approximately 207 tested specimens with a variety of I/b, b, FA, CA, SH, SS, M, SS/SH, nS, T, and ana A, were collected and reviewed using a variety of analytical approaches with the goal of: (i) providing most effortless equations to be used by practicing engineers and scholars in their GPC mix design works; (ii) clarifying the effects of each mix proportion parameters and curing temperatures and ages on the CS of GPC incorporated nS; (iii) to quantify and offer systematic multiscale models for forecasting the CS of GPC utilizing eleven variable input parameters; (iv) using statistical assessment methods such as MAE, RMSE, $R^{2}, O B J$, and SI to find the most authoritative model to forecast the CS of GPC composites incorporated nS from various model strategies (LR, NLR, MLR, ANN, and M5P).

\section{Methodology}

The authors conducted an extensive search of several databases, including Research Gate, Science Direct, Google Scholar, Scopus, and the web of science. A wealth of papers was discovered discussing the effect of various NP types on the properties of geopolymer paste composites. However, a limited number of documents were found regarding the impact of NPs on the properties of GPC composites. Totally, 207 datasets of the CS values were obtained. In the literature, a wide range of NPs like nS, nC, nA, CNT, nM, nT were consumed to improve various properties of the GPC composites, with nS being the most frequent, as can be seen in Table 1. Therefore, in this study, the authors take those articles that used nS to improve various properties of the GPC composites.

In the modeling process, eleven input parameters were used, limiting the authors' ability to utilize a greater number of data in the created models. The gathered datasets were statistically analyzed and classified into three groups. The models were built using the larger group, which included 135 datasets. The second group is made up of 36 datasets that were used to test the created models, and the final group is made up of 36 datasets that were consumed to validate the suggested models (Golafshani et al., 2020; Faraj et al., 2021). Table 2 shows the dataset ranges, including all significant parameters and the observed CS of the GPC incorporated $\mathrm{nS}$. The input dataset contains the following values: $\mathrm{I} / \mathrm{b}$ ranges from 0.4 to $0.4, \mathrm{~b}$ ranges from $300-500 \mathrm{~kg} / \mathrm{m}^{3}$, $\mathrm{FA}$ ranges from $490-990$ $\mathrm{kg} / \mathrm{m}^{3}$, CA ranges from $810-1470 \mathrm{~kg} / \mathrm{m}^{3}$, SH ranges from $18.17-159.75 \mathrm{~kg} / \mathrm{m}^{3}$, SS ranges from 40.8-187.5 kg/m ${ }^{3}$, M ranges from 4-16 M, SS/SH ranges from $0.33-3, \mathrm{nS}$ ranges from $0-60 \mathrm{~kg} / \mathrm{m}^{3}, \mathrm{~T}$ ranges from $23-70^{\circ} \mathrm{C}$, A ranges from $0.5-180$ days, and CS ranges from 3.2-81.3 MPa. The previous datasets were used to propose various models such as LR, NLR, MLR, ANN, and M5P to estimate the CS of GPC incorporated nS; then, the developed models were evaluated using statistical criteria such as $\mathrm{R}^{2}$, RMSE, MAE, SI, and OBJ to determine the most reliable and accurate model. Additional details about this work's methodology are shortened in a flow chart, as illustrated in Figure 1.

\section{Statistical Assessment}

Sufficient information about each variable input model parameter is provided in the following sections through 4.1 to 4.12 .

\subsection{Alkaline solution to binder ratio (I/b)}

Based on the collected datasets, the ratio of I/b of the GPC mixtures modified with $\mathrm{nS}$ was in the range of 0.4 to 0.6 , with the average and standard deviations of 0.49 and 0.05 , respectively. Also, regarding other statistical analyses, it was found that the variance was 0.002 , skewness was 0.66 , and the kurtosis was -0.25 . Figure 2 depicts the relationship between $\mathrm{CS}$ and $\mathrm{l} / \mathrm{b}$ with histograms of GPC mixtures incorporated $\mathrm{nS}$.

\subsection{Binder content (b)}

According to Table 1, F, GGBFS, MK, SF, RHA, and NP are those ashes that scholars used as source binder materials to produce GPC composites. The ranges of these binders were between 300 to $500 \mathrm{~kg} / \mathrm{m}^{3}$, with the average and standard deviations of $417 \mathrm{~kg} / \mathrm{m}^{3}$ and $51.8 \mathrm{~kg} / \mathrm{m}^{3}$, correspondingly. At the same time, other statistical assessment tools like variance, skewness, and kurtosis were $2689,0.11$, and -0.81 , respectively, for the collected datasets. Figure 3 illustrates the CS and b content variation and frequencies of the gathered data of GPC mixtures incorporated nS.

\section{3 Fine aggregate content (FA)}

Like traditional concrete mixtures, natural and crushed sands were used as the FA in GPC mixtures. The FA should be satisfied with the requirements of ASTM standards. According to gathered datasets from the literature article, it was found that the range of FA was between 490 to $990 \mathrm{~kg} / \mathrm{m}^{3}$, with an average of 681 $\mathrm{kg} / \mathrm{m}^{3}$ and standard deviations of $135.2 \mathrm{~kg} / \mathrm{m}^{3}$. More information regarding other statistical assessment tools can be found in figure 4 . 


\subsection{Coarse aggregate content (CD)}

Natural, crushed, and recycled aggregates are those forms of aggregates that were used as the CA in geopolymer concrete mixtures, just like conventional concrete mixtures. Same as FA, the CA should have all the properties which are required by ASTM standards. Regarding the ranges of CA, it was concluded that the contents of CA in past research varied between 810 to $1470 \mathrm{~kg} / \mathrm{m}^{3}$ with an average of $1113.8 \mathrm{~kg} / \mathrm{m}^{3}$ and standard deviations of $183.2 \mathrm{~kg} / \mathrm{m}^{3}$. On the other hand, the variance, skewness, and kurtosis were $33580,-0.19,-0.71$, respectively. Also, the correlations between the CS of tested datasets and the CA contents can be found in figure 5 .

\section{5 $\mathrm{NaOH}$ content (SH)}

Pellets and flakes are two forms of $\mathrm{SH}$ in a solid state with a purity above $97 \%$. This material is mixed with the required amount of water to prepare a solution of SH with the required molarity. In this study, according to the collected datasets, the amount of SH in a $1 \mathrm{~m}^{3}$ of GPC mixture incorporated nS was in the range between 18.1 to $159.7 \mathrm{~kg} / \mathrm{m}^{3}$, with an average of $71.3 \mathrm{~kg} / \mathrm{m}^{3}$ and a standard deviation of $33.9 \mathrm{~kg} / \mathrm{m}^{3}$. Extra information about other statistical assessment criteria and correlations between the CS and SH content can be found in figure 6 .

\section{$4.6 \mathrm{Na}_{2} \mathrm{SiO}_{3}$ content (SS)}

Water glass or sodium silicate is present in a liquid form which mainly consists of $\mathrm{Na}_{2} \mathrm{O}, \mathrm{SiO}_{2}$, and $\mathrm{H}_{2} \mathrm{O}$. Based on the previous research conducted on the GPC mixtures incorporated $\mathrm{nS}$, the range of SS was found in between 40.8 to $187.5 \mathrm{~kg} / \mathrm{m}^{3}$, with an average of $134.4 \mathrm{~kg} / \mathrm{m}^{3}$ and the standard deviations of 35.6 $\mathrm{kg} / \mathrm{m}^{3}$. In comparison, other stats information like variance, skewness, and kurtosis were $1268,-1.42,1.55$, correspondingly. Furthermore, the correlations between the CS and the SS contents of GPC can be found in figure 7.

\subsection{Molarity (M)}

In the field of GPC science, the concentrations of sodium hydroxide inside water were called molarity. The authors of this study found that the molarity of SH in the collected papers was in the range between 4 to $16 \mathrm{M}$, with an average of $11.9 \mathrm{M}$ and standard deviations of $3.3 \mathrm{M}$. Also, it was found that the variance of the reviewed datasets was 11.1, the skewness was -1.4, and kurtosis was 1.3. The variations between the CS and M with the frequency of their datasets of GPC incorporated nS are presented in figure 8.

\section{$4.8 \mathrm{Na}_{2} \mathrm{SiO}_{3} / \mathrm{NaOH}(\mathrm{SS} / \mathrm{SH})$}

This parameter consists of a mixture of SS and SH with the required molarity. Usually, it is prepared about 24 hrs before mixing the GPC ingredients. According to the gathered datasets, this parameter was used in the range between 0.33 to 3 , with an average of 2.05 and standard deviations of 0.76 . Also, the other statistical criteria were found to be $0.59,-1.2$, and 0.22 for the variance, skewness, and kurtosis, respectively. Moreover, correlations between the CS and the $\mathrm{SS} / \mathrm{SH}$ are illustrated in figure 9 , with the frequencies of their datasets.

\subsection{Nano-silica content (nS)}

As mentioned earlier, nS was the most frequently NPs that scholars used to improve various properties of GPC composites. It was used as a binder replacement or just by the addition. Table 1 shows the different properties of $\mathrm{nS}$ and other NP types that were utilized in GPC composites. Regarding the values of this input model parameter, it was found that the range of $\mathrm{nS}$ was used to improve GPC composites in the range between 0 to $60 \mathrm{~kg} / \mathrm{m}^{3}$, with an average of $11.6 \mathrm{~kg} / \mathrm{m}^{3}$, and the standard deviations of $14.5 \mathrm{~kg} / \mathrm{m}^{3}$. Similarly, other statistical criteria with the correlations between the CS and the nS content can be found in figure 10 .

\subsection{Curing temperatures $(T)$}

Ambient, steam, and oven curing regimes were commonly used to cure GPC composites. One of the reasons behind using NPs in GPC composites is to take away from the oven and steam curing methods and go toward ambient curing methods. Based on the collected datasets, GPC specimens modified with nS were cured in the temperature ranges between 23 to $70^{\circ} \mathrm{C}$, with an average of $42.05^{\circ} \mathrm{C}$ and the standard deviations of $17.4^{\circ} \mathrm{C}$. Also, other statistical assessment tolls like variance, skewness, and kurtosis were $303.9,0.11$, and -1.92 , respectively. The variations of the CS with the nS content and the frequencies of nS datasets are presented in figure 11.

\subsection{Age of specimens (A)}

To gain sufficient early and late CS, the curing ages should be extended to promote the polymerization process, which strengthens geopolymers. Thus, based on the collected datasets, the cure time for GPC incorporated nS ranged from 0.5 to 180 days, with an average of 28 days and standard deviations of 31.8 
days. Similarly, the published datasets' variance, skewness, and kurtosis were 1012.8, 2.36, and 6.96, respectively. The relationships between the CS and the specimen ages with the frequencies of collected data are shown in figure 12.

\subsection{Compressive strength (CS)}

An applied vertical load per unit area of the GPC specimens was known as normal stress or compressive strength. This property is one of the critical mechanical properties of GPC composites. As shown in Table 2, the range of the CS for the gathered datasets was in the range between 3.2 o $81.3 \mathrm{MPa}$, with an average of $36.2 \mathrm{MPa}$ and standard deviations of $17.52 \mathrm{MPa}$. At the same time, other statistical criteria like variance, skewness, and kurtosis were $307,0.15$, and -0.75 , respectively.

\section{Modeling}

Based on the coefficients of the determinations $\left(R^{2}\right)$ of the collected input model parameters, as shown in figure 2 to figure 12 , there is no direct relationship between the CS and any individual input model parameters. Therefore, multiscale model techniques, including M5P, MLR, ANN, LR, and NLR are employed to develop empirical models to forecast the CS of GPC composites incorporated nS in different mix proportion parameters, curing regimes, and specimens ages.

For creating the models, the collected datasets are split into three categories. The models were built using the larger group, which included 135 datasets. The second group is made up of 36 datasets that were utilized to test the created models, and the final group is made up of 36 datasets that were consumed to validate the suggested models (Golafshani et al., 2020; Faraj et al., 2021). The forecasts of various models were compared employing these criteria: (1) The model's validity should be established scientifically; (2) Between estimated and tested data, it should have a lower percentage of error; (3) The RMSE, OBJ, and SI values of the suggested equations should be low, while $\mathrm{R}^{2}$ value should be high.

\section{a. Linear regression model (LR)}

LR is one of the standard methods that scholars used to estimate and forecast the CS of concrete composites (Faraj et al., 2021). This model has a general form, as depicted in equation (1) (Ahmed et al., 2021b).

$$
C S=a+b(x 1)
$$

Where, $C S, x 1$, aand $b$ represents the compressive strength, one of the variable input parameters, and models parameters, respectively. This equation contains just one variable of input data, so to have more practical and reliable investigations, equation (2) is suggested, which contains a wide range of input variable data parameters that can cover all of the geopolymer concrete mixture proportions and curing conditions, as well as curing ages.

$$
C S=a+b\left(\frac{l}{b}\right)+c(b)+d(F A)+e(C A)+f(S H)+g(S S)+h(M)+i\left(\frac{S S}{S H}\right)+j(n S)+k(T)+l(A)
$$

As mentioned earlier, all these main variables in equation (2) were described except that the a, b, c, d, e, f, g, h, i, j, k, and I are the model parameters. Equation (2) is a one-of-a-kind equation because it incorporates a large number of independent variables to generate GPC-incorporated nS that may be extremely useful in the construction industry. On the other hand, because all variables can be adjusted linearly, the proposed equation (2) can be considered an extension of equation (1).

\section{b. Nonlinear regression model (NLR)}

In terms of the NLR, equation (3) may be regarded as a general form for proposing an NLR model (Mohammed et al., 2020). The interrelationships between the variables in equations (1) and (2) can be used to calculate the CS of normal geopolymer concrete mixtures and geopolymer concrete mixtures modified with ns using equation (3).

$C S=a *\left(\frac{l}{b}\right)^{b} *(b)^{C} *(F A)^{d} *(C A)^{e} *(S H)^{f} *(S S)^{g} *(M)^{h} *\left(\frac{S S}{S H}\right)^{i} *(T)^{j} *(A)^{k}+l *\left(\frac{l}{b}\right)^{m} *(b)^{n} *(F A)^{o} *(C A)^{p} *(S H)^{q} *(S S)^{r}$

Where: all of the variables in this equation were provided earlier, except that the a, b, c, d, e, f, g, h, i, j, k, l, m, n, o, p, q, r, s, t, u, and v are described as a model parameter.

\section{c. Multi-logistic regression model (MLR)}

As with the previous models, the collected datasets were subjected to multi-logistic regression analysis, and the general form of the MLR is shown in equation (4) based on the research conducted by Mohammed et al. (2021) and Faraj et al. (2021). MLR is used to distinguish a nominal predictor variable from one or more independent variables.

$C S=$ a47208eenmodelpredictionsofcompressivestrengthofflyashbasedgeopolymerconcretemixturesusingtrainingdata $*\left(\frac{l}{b}\right)^{b} *(b)^{C} *(F$ 
Where: all of the variables in this equation were provided earlier. Moreover, in this equation, the value of nS should be greater than 0.

\section{d. Artificial neural network (ANN)}

ANN is a powerful simulation software designed for data analysis and computation that processes and analyzes data similarly to a human brain. This machine learning tool is widely used in construction engineering to forecast the future behavior of a variety of numerical problems (Mohammed, 2018; Sihag et al., 2018).

An ANN model is generally divided into three main layers: input, hidden, and output. Depending on the proposed problem, each input and output layer can be one or more layers. On the other hand, the hidden layer is usually ranged for two or more layers. Although the input and output layers are generally determined by the collected data and the purpose of the designed model, the hidden layer is determined by the rated weight, transfer function, and bias of each layer to other layers. A multi-layer feed-forward network is constructed using a combination of proportions, weight/bias, and several parameters as inputs, including $(I / b, b, F A, C A, \ldots)$, and the output ANN is compressive strength.

There is no standardized method for designing network architecture. As a result, the number of hidden layers and neurons is determined through a trial and error procedure. One of the primary goals of the network's training process is to determine the optimal number of iterations (epochs) that provide the lowest MAE, RMSE, and best $\mathrm{R}^{2}$-value close to one. The effect of several epochs on lowering the MAE and RMSE has been studied. For the purpose of training the designed ANN, the collected data set (a total of 207 data) was divided into three parts. Approximately $70 \%$ of the collected data was used as training data to train the network. The data set was tested with $15 \%$ of the total data, and the remaining data were used to validate the trained network (Demircan et al., 2011). The designed ANN was trained and tested for various hidden layers to determine optimal network structure based on the fitness of the predicted CS of GPC incorporated $\mathrm{nS}$ with the CS of the actual collected data. It was observed that the ANN structure with two hidden layers, 24 neurons, and a hyperbolic tangent transfer function was a best-trained network that provides a maximum $\mathrm{R}^{2}$ and minimum both MAE and RMSE (shown in Table 3 ). As a part of this work, an ANN model has been used to estimate the future value of the CS of GPC incorporated nS. The general equation of the ANN model is shown in equations (5), (6), and (7).

From linear node 0:

$$
C S=\text { Threshold }+\left(\frac{\text { Node1 }}{1+e^{-B 1}}\right)+\left(\frac{\text { Node2 }}{1+e^{-B 2}}\right)+
$$

From sigmoid node 1:

$$
B 1=\text { Threshold }+\square(\text { Attribute } * \text { Variable })
$$

From sigmoid node 2:

$$
B 2=\text { Threshold }+\square(\text { Attribute } * \text { Variable })
$$

\section{e. M5P-tree model (M5P)}

The M5P model tree reconstructs Quinlan's M5P-tree algorithm (Quinlan, 1992), a decision tree with a linear regression function added to the leaves nodes. The decision tree encapsulates the algorithms in a tree structure formed by nodes formed during training on data. The nodes of the decision tree are classified as root nodes, internal nodes, and leaf nodes. Nodes are interconnected through branches until the leaves are reached (Malerba et al., 2004). Mohammed (2018) also introduced the M5P-tree as a robust decision tree learner model for regression analysis. The linear regression functions are placed at the terminal nodes by this learner algorithm. Classifying all data sets into multiple sub-spaces assigns a multivariate linear regression model to each sub-space. The M5Ptree algorithm operates on continuous class problems rather than discrete segments and is capable of handling tasks with a high number of dimensions. It reveals the developed information of each linear model component constructed to estimate the nonlinear correlation of the data sets. The information about division criteria for the M5-tree model is obtained through the error calculation at each node. The standard deviation of the class entering that node at each node is used to analyze errors. At each node, the attribute that maximizes the reduction of estimated error is used to evaluate any task performed by that node. As a result of this division in the M5P tree, a large tree-like structure will be generated, which will result in overfitting. The enormous tree is trimmed in the followed step, and linear regression functions restore the pruned subtrees. The general equation form of the M5P-tree model is the same as the linear regression equation, as shown in equation (8).

$$
C S=a+b\left(\frac{l}{b}\right)+c(b)+d(F A)+e(C A)+f(S H)+g(S S)+h(M)+i\left(\frac{S S}{S H}\right)+j(n S)+k(T)+l(A)
$$

Where: the descriptions of all of the variables in this equation (8) were provided earlier.

\section{Model Efficiencies}


To rate and assess the proposed models' accuracy, various performance stats tools such as $\mathrm{R}^{2}$, RMSE, MAE, SI, and OBJ were used, which they have the following equations:

$$
R^{2}=\left(\frac{\sum_{p=1}^{p}\left(y_{p}-y\right)\left(x_{p}-x^{\prime}\right)}{\sqrt{\left[\sum_{p=1}^{p}\left(y_{p}-y^{\prime}\right)^{2}\right]\left[\sum_{p=1}^{p}\left(x_{p}-x^{\prime}\right)^{2}\right]}}\right)^{2}
$$

9

$$
\begin{aligned}
& R M S E=\sqrt{\frac{\sum_{p=1}^{p}\left(x_{p}-y_{p}\right)^{2}}{n}} \\
& M A E=\frac{\sum_{p=1}^{p}\left|\left(x_{p}-y_{p}\right)\right|}{n} \\
& S I=\frac{R M S E}{y^{\prime}} . \\
& O B J=\left(\frac{n_{t r}}{n_{\text {all }}} * \frac{R M S E_{t r}+M A E_{t r}}{R_{t r}^{2}+1}\right)+\left(\frac{n_{t s t}}{n_{\text {all }}} * \frac{R M S E_{t s t}+M A E_{t s t}}{R_{t s t}^{2}+1}\right)+\left(\frac{n_{\text {val }}}{n_{\text {all }}} * \frac{R M S E_{\text {val }}+M A E_{\text {val }}}{R_{\text {val }}^{2}+1}\right)
\end{aligned}
$$

Where:

$x_{p}$ and $y_{p}$ are estimated and tested CS values, $y^{\prime}$ and $x^{\prime}$ are averages of experimentally tested and the estimated values from the models, respectively. tr, tst, and val are referred to the training, testing, and validating datasets, respectively, and $n$ is the number of datasets. Except for the $R^{2}$ value, zero is the optimal value for all other evaluation parameters. However, one is the highest benefit for $\mathrm{R}^{2}$. When it comes to the SI parameter, a model has bad performance when it is $>0.3$, acceptable performance when it is $0.2 \mathrm{SI} 0.3$, excellent performance when it is $0.1 \mathrm{SI} 0.2$, and great performance when it is $0.1 \mathrm{SI} 0.1$ (Faraj et al., 2021). Furthermore, the OBJ parameter was employed as a performance measurement parameter in equation (13) to measure the efficiency of the suggested models.

\section{Results And Analysis a) LR model}

The output of this model revealed that the $\mathrm{l} / \mathrm{b}, \mathrm{SS} / \mathrm{SH}$, and $\mathrm{M}$ are those parameters that have a greater impact on the CS of GPC incorporated $\mathrm{nS}$ than other parameters. This result was confirmed by a wide range of published experimental works in the literature (Hardjito et al., 2004; Deb et al., 2014; Oyebisi et al., 2020). Equation (14) with the weight of each model parameter is the output of this model. Optimizing the sum of error squares and the least square method, which were implemented in an Excel program using Solver to calculate the ideal value for the equation in one cell designated the objective cell, were used to determine the weighting of each parameter on the CS of GPC mixtures incorporating nS. The values of other equation cells constrained this object cell in the worksheet (Mohammed et al., 2021; Faraj et al., 2021).

$C S=110.06-66.6\left(\frac{l}{b}\right)+0.06(b)-0.01(F A)+0.005(C A)-0.34(S H)+0.12(S S)-3.12(M)-13.9\left(\frac{S S}{S H}\right)-0.18(n S)+0.11(T)+0.23(A$

Figures 13a, b, and c depict the relationship between estimated and real CS of GPC mixtures incorporated nS for training, testing, and validating datasets, respectively. Moreover, this model was evaluated by some statistical assessment tools, and it was observed that the $\mathrm{R}^{2}$ and RMSE for the training datasets were equals to $0.7989,7.65 \mathrm{MPa}$, respectively, and as illustrated in figure 25 and 26, the other statistical criteria like OBJ and SI were 8.05 MPa and 0.209. Finally, utilizing training, testing, and validating datasets, the residual CS for the LR model for the forecasted and observed CS was displayed in figure 14 .

\section{b) NLR model}

The correlations between the actual and forecasted CS of GPC mixtures incorporated nS are presented in figures 15a, b, and c for the training, testing, and validating datasets, correspondingly. As shown in equation (15), the weight of the model parameters demonstrated that the l/b, $\mathrm{SH}$, and $\mathrm{M}$ are those input variable parameters that significantly affect the CS of geopolymer concrete mixtures modified with nS. This result was also well-validated in the previous experimental laboratory research works (Hardjito et al., 2004; Aliabdo et al., 2016; Ghafoor et al., 2021). 
$C S=-4643005 *\left(\frac{l}{b}\right)^{3.78} *(b)^{1.34} *(F A)^{-1.87} *(C A)^{0.08} *(S H)^{5.5} *(S S)^{-7.85} *(M)^{2.72} *\left(\frac{S S}{S H}\right)^{-6.06} *(T)^{-0.53} *(A)^{0.02}+73.89 *$

Similar to the LR model, this model was also assessed by some statistical criteria, and it was found that the R2, RMSE, OBJ, and SI of the training datasets were equal to $0.8792,5.92 \mathrm{MPA} 5.80 \mathrm{MPa}$, and 0.162 , respectively. Furthermore, the difference between actual and estimated CS of geopolymer concrete mixtures modified with $\mathrm{nS}$ can be found in figure 16 for all the validating, testing, and training datasets.

\section{c) MLR model}

Equation (16) shows the generated models for the MLR model with various variable parameters. The most significant independent factors that impact the CS of the geopolymer concrete mixtures modified with nS in the MLR model were SS content, age of the specimens, and curing temperatures, which are matched with some experimental studies published in the past articles (Jindal et al., 2017; Hassan et al., 2019; Ghafoor et al., 2021).

CS $=29.0347208$ eenmodelpredictionsofcompressivestrengthofflyashbasedgeopolymerconcretemixturesusingtrainingdataXXXXXXXXX $*$

Figure 17a was created by utilizing training datasets to depict the anticipated and measured CS correlations for the GPC mixtures incorporated nS. Furthermore, similar to the earlier models, this model was tested using two parts of data (validating and testing data) to demonstrate its efficacy for variables not included in the model data (training data). The findings indicate that by substituting the independent variables into the established equation, this model can predict the CS of GPC, as illustrated in figure.17b and c. the value of $\mathrm{R}^{2}$, RMSE for this developed model are $0.7787,8.02 \mathrm{MPa}$, respectively, for the training datasets. Also, as depicted in figure 25 and 26, the value of other statistical assessment tools like OBJ and SI values was observed at 8.8 MPa and 0.22 , respectively. Lastly, utilizing validating, training, and testing data, the residual CS for the MLR model for predicted and observed CS of GPC incorporated nS was displayed in figure 18.

\section{d) ANN model}

In this study, the authors tried a lot to get the high efficiency of the ANN by applying different numbers of the hidden layer, neurons, momentum, learning rate, and iteration, as can be seen in Table 3. Lastly, it was observed that when the ANN has two hidden layers, 24 neurons ( 12 for left side and 12 for the right side as shown in figure 19), 0.2 momenta, 0.1 learning rate, and 2000 iteration give best-predicted values of the CS of the GPC mixtures incorporated nS. The ANN model was equipped with the training datasets, accompanied by testing and validating datasets to predict the compression strength values for the correct input parameters. The comparison between estimated and experimentally tested CS of GPC mixtures incorporated nS for training, testing, and validating datasets are presented in figure $20 a, b$, and $c$. The consumed data have $a+10 \%$ and $-20 \%$ error line for the training and testing datasets, and $\pm 10 \%$ for the validating datasets, which is better than the other developed models. Furthermore, this model has a better performance than other models to predict the CS of the GPC incorporated $n S$ based on the value of OBJ and SI illustrated in Figures 25 and 26. Also, the value of $\mathrm{R}^{2}=0.9771, \mathrm{MAE}=2.83 \mathrm{MPa}$, and $\mathrm{RMSE}=3.89$ $\mathrm{MPa}$. Finally, the differences in the value of the CS for estimated and tested GPC mixtures incorporated nS can be found in figure 21 by consuming all the datasets.

\section{e) M5P model}

The predicted and observed CS of the GPC mixtures incorporated nS for whole the datasets are shown in figure 22a, b, and c. Similar to the other models, it was discovered that the I/b and M of the GPC mixtures incorporated nS has the greatest impact on the CS of the GPC mixtures incorporated nS, which agrees with experimental findings in the past studies (Hardjito et al., 2004; Aliabdo et al., 2016; Ghafoor et al., 2021). Figure 23 shows the tree-shaped branch correlations. Also, the model (in equation (17)) parameters are summarized in Table 4, and the model variables will be selected based on the linear tree registration function.

$$
C S=a+b\left(\frac{l}{b}\right)+C(b)+d(F A)+e(C A)+f(S H)+g(S S)+h(M)+i\left(\frac{S S}{S H}\right)+j(n S)+k(T)+l(A)
$$

For all of the training, testing, and validation datasets, there is a 20 percent error line. Finally, for all datasets, the residual CS for the M5P model was displayed in figure 24 for both predicted and observed CS. Furthermore, this model's R², RMSE, MAE, OBJ, and SI evaluation criteria are 0.9454, 5.59 MPa, 4.45 MPa, 6.0 $\mathrm{MPa}$, and 0.153 , respectively, for the training datasets.

\section{Proposed Models Performance}

As early mentioned, the efficiency of the developed models was evaluated by employing these five stats tools: RMSE, MAE, SI, OBJ, and R². When compared to the LR, NLR, MLR, and M5P models, the ANN model has a higher $\mathrm{R}^{2}$ with lower RMSE and MAE values, as well as lower OBJ and SI values. 
In addition, figure 27 shows a comparison of model predictions of the CS of GPC mixtures incorporated nS based on the testing datasets. Furthermore, figures $14,16,18,21$, and 24 display the residual errors for the CS by consuming all the datasets. The whole figures show that the estimated and tested CS values for the ANN model are close, indicating that the ANN model is more accurate than other models.

Figure 25 shows the OBJ values for all of the proposed models. The OBJ is $8.05,5.8,8.8,3.59$, and 6.0 for LR, NLR, MLR, ANN, and M5P, respectively. The ANN model has a lower OBJ value, about $124 \%$ less than the LR model, $61.5 \%$ less than the NLR model, $145 \%$ less than the MLR model, and $67 \%$ less than the M5P model. This also emphasized that the ANN model better forecasts the CS of GPC incorporated nS.

In addition, figure 26 shows the SI values for the created models during the training, validating, and testing phases. The SI values for NLR and ANN models for the entire training, testing, and validating datasets were between 0.1 and 0.2 , signalizing good accuracy for these models. While, for the other remaining models, the values of SI were between 0.2 and 0.3 , this result revealed that the performance of the LR, MLR, and M5P models are in fair condition. Similar to other statistical assessment criteria, the ANN model has smaller SI values among the entire models. The ANN model has lower SI values (for training datasets) than the LR, NLR, MLR, and M5P models by $97.2 \%, 52.8 \%, 107.5 \%$, and $44.3 \%$, respectively. This also demonstrated that when forecasting the CS of GPC mixtures incorporated $\mathrm{nS}$, the ANN model is more efficient and performs better than the other models.

\section{Conclusions}

Using new scientifical technics like empirical correlations and neural networks to estimate the CS of GPC mixtures incorporated nS can save time and money. LR, NLR, MLR, ANN, and M5P models were used in this article to develop predictive models for estimating the CS of GPC mixtures incorporated nS. Based on the extensive revision and data gathering, the following conclusion can be drawn:

1- The average amount of $\mathrm{nS}$ used in GPC mixtures was $11.6 \mathrm{~kg} / \mathrm{m}^{3}$, or approximately $3 \%$ of the binder content. Additionally, the percentage of nS substituted with binder varied between 0 and $60 \mathrm{~kg} / \mathrm{m}^{3}$.

2- The LR, NLR, MLR, ANN, and M5P models were all successfully utilized to create predictive models for the CS of the GPC mixtures incorporated nS. The estimated CS closely matched experimentally measured CS of GPC mixtures contained nS.

3- The whole created models were satisfied all the statistical assessment criteria such as $\mathrm{R}^{2}$, RMSE, MAE, OBJ, and SI.

4- The ANN model outperforms the other three models based on statistical evaluation and sensitivity analysis. For the training, testing, and validating datasets, the $\mathrm{R}^{2}$ values are $0.9771,0.9777$, and 0.9923 , respectively. Furthermore, the RMSE, MAE, OBJ, and SI stats criteria for the training dataset for the ANN model are $3.892 \mathrm{MPa}, 2.832 \mathrm{MPa}, 3.59 \mathrm{MPa}$, and 0.106, respectively. Consequently, the ANN model has greater generality and suitability in the initiatory design of GPC mixtures incorporated nS.

5- The two-layer ANN model with twelve neurons in each layer is the best model combination for estimating the CS of GPC mixtures incorporated nS.

6- The sequence for suitability and having greater performances of the proposed models are as follows: ANN, NLR, M5P, LR, and MLR.

7- The obtained results indicate that the most significant variable parameters for estimating the CS of GPC mixtures contained nS are the I/b, SS/SH, M, T, and A.

\section{Declarations}

\section{Author contribution:}

Hemn Unis Ahmed (corresponding author): idea of concept; planning; validation; resources; data curation; writing-original draft; writing-review and editing for this manuscript.

Ahmed S. Mohammed: Planning, validation; resources; data curation; writing-review for this manuscript.

Azad A. Mohammed: planning and designing; validation; writing-review for this manuscript.

\section{Availability of data and materials:}

Not applicable.

\section{Ethical approval:}

Not applicable.

\section{Consent to participate:}


Not applicable.

\section{Consent to publication:}

Not applicable.

\section{Competing interests:}

The authors declare no competing interests.

\section{Funding:}

Not applicable.

\section{References}

1. Abdel-Gawwad, H. A., \& Abo-El-Enein, S. A. (2016). A novel method to produce dry geopolymer cement powder. HBRC journal, 12(1), 1324. https://doi.org/10.1016/j.hbrcj.2014.06.008

2. Abdullah, W. A., Ahmed, H. U., Alshkane, Y. M., Rahman, D. B., Ali, A. O., \& Abubakr, S. S. (2021). The Possibility of Using Waste PET Plastic Strip to Enhance the Flexural Capacity of Concrete Beams. Journal of Engineering Research, 9. https://doi.org/10.36909/jer.v9ilCRIE.11649

3. Adak, D., Sarkar, M., \& Mandal, S. (2017). Structural performance of nano-silica modified fly-ash based geopolymer concrete. Construction and Building Materials, 135, 430-439. https://doi.org/10.1016/j.conbuildmat.2016.12.111

4. Ahmed, H. U., Faraj, R. H., Hilal, N., Mohammed, A. A., \& Sherwani, A. F. H. (2021a). Use of recycled fibers in concrete composites: A systematic comprehensive review. Composites Part B: Engineering, 108769. https://doi.org/10.1016/j.compositesb.2021.108769

5. Ahmed, H. U., Mohammed, A. S., Mohammed, A. A., \& Faraj, R. H. (2021b). Systematic multiscale models to predict the compressive strength of fly ashbased geopolymer concrete at various mixture proportions and curing regimes. Plos one, 16(6), e0253006. https://doi.org/10.1371/journal.pone.0253006

6. Aliabdo, A. A., Abd Elmoaty, M., \& Salem, H. A. (2016). Effect of water addition, plasticizer and alkaline solution constitution on fly ash based geopolymer concrete performance. Construction and Building Materials, 121, 694-703. https://doi.org/10.1016/j.conbuildmat.2016.06.062

7. Angelin Lincy, G., \& Velkennedy, R. (2020). Experimental optimization of metakaolin and nanosilica composite for geopolymer concrete paver blocks. Structural Concrete. https://doi.org/10.1002/suco.201900555

8. Assaedi, H., Shaikh, F. U. A., \& Low, I. M. (2016). Influence of mixing methods of nano silica on the microstructural and mechanical properties of flax fabric reinforced geopolymer composites. Construction and Building Materials, 123, 541-552. https://doi.org/10.1016/j.conbuildmat.2016.07.049

9. Behfarnia, K., \& Rostami, M. (2017). Effects of micro and nanoparticles of SiO2 on the permeability of alkali activated slag concrete. Construction and building materials, 131, 205-213. https://doi.org/10.1016/j.conbuildmat.2016.11.070

10. Çevik, A., Alzeebaree, R., Humur, G., Niş, A., \& Gülşan, M. E. (2018). Effect of nano-silica on the chemical durability and mechanical performance of fly ash based geopolymer concrete. Ceramics International, 44(11), 12253-12264. https://doi.org/10.1016/j.ceramint.2018.04.009

11. Davidovits, J. (2015). Geopolymer Chemistry and Applications. 4-th edition. J. Davidovits. -Saint-Quentin, France.

12. Deb, P. S., Nath, P., \& Sarker, P. K. (2014). The effects of ground granulated blast-furnace slag blending with fly ash and activator content on the workability and strength properties of geopolymer concrete cured at ambient temperature. Materials \& Design (1980-2015), 62, 32-

39. https://doi.org/10.1016/j.matdes.2014.05.001

13. Demircan, E., Harendra, S., \& Vipulanandan, C. (2011). Artificial neural network and nonlinear models for gelling time and maximum curing temperature rise in polymer grouts. Journal of materials in civil engineering, 23(4), 372-377. https://doi.org/10.1061/(ASCE)MT.1943-5533.0000172

14. Emad, H., Soufi, W., Elmannaey, A., Abd-El-Aziz, M., \& EL-Ghazaly, H. Effect of Nano-Silica on the Mechanical Properties of Slag Geopolymer Concrete.

15. Etemadi, M., Pouraghajan, M., \& Gharavi, H. (2020). Investigating the effect of rubber powder and nano silica on the durability and strength characteristics of geopolymeric concretes. Journal of civil Engineering and Materials Application, 4(4), 243-252. https://doi.org/10.22034/jcema.2020.119979

16. Faraj, R. H., Mohammed, A. A., Mohammed, A., Omer, K. M., \& Ahmed, H. U. (2021). Systematic multiscale models to predict the compressive strength of self-compacting concretes modified with nanosilica at different curing ages. Engineering with Computers, 1-24. https://doi.org/10.1007/s00366-02101385-9

17. Ghafoor, M. T., Khan, Q. S., Qazi, A. U., Sheikh, M. N., \& Hadi, M. N. S. (2021). Influence of alkaline activators on the mechanical properties of fly ash based geopolymer concrete cured at ambient temperature. Construction and Building Materials, 273,

121752. https://doi.org/10.1016/j.conbuildmat.2020.121752

18. Gholampour, A., Mansouri, I., Kisi, O., \& Ozbakkaloglu, T. (2020). Evaluation of mechanical properties of concretes containing coarse recycled concrete aggregates using multivariate adaptive regression splines (MARS), M5 model tree (M5Tree), and least squares support vector regression (LSSVR) models. Neural Computing and Applications, 32(1), 295-308. https://doi.org/10.1007/s00521-018-3630-y 
19. Golafshani, E. M., \& Behnood, A. (2018). Application of soft computing methods for predicting the elastic modulus of recycled aggregate concrete. Journal of cleaner production, 176, 1163-1176. https://doi.org/10.1016/j.jclepro.2017.11.186

20. Golafshani, E. M., Behnood, A., \& Arashpour, M. (2020). Predicting the compressive strength of normal and High-Performance Concretes using ANN and ANFIS hybridized with Grey Wolf Optimizer. Construction and Building Materials, 232, 117266. https://doi.org/10.1016/j.conbuildmat.2019.117266

21. Hardjito, D., Wallah, S. E., Sumajouw, D. M., \& Rangan, B. V. (2004). On the development of fly ash-based geopolymer concrete. Materials Journal, 101(6), 467-472.

22. Hassan, A., Arif, M., \& Shariq, M. (2019). Effect of curing condition on the mechanical properties of fly ash-based geopolymer concrete. SN Applied Sciences, 1(12), 1-9. https://doi.org/10.1007/s42452-019-1774-8

23. Ibrahim, M., Johari, M. A. M., Maslehuddin, M., \& Rahman, M. K. (2018a). Influence of nano-SiO2 on the strength and microstructure of natural pozzolan based alkali activated concrete. Construction and Building Materials, 173, 573-585. https://doi.org/10.1016/j.conbuildmat.2018.04.051

24. Ibrahim, M., Johari, M. A. M., Rahman, M. K., Maslehuddin, M., \& Mohamed, H. D. (2018b). Enhancing the engineering properties and microstructure of room temperature cured alkali activated natural pozzolan based concrete utilizing nanosilica. Construction and Building Materials, 189, 352365. https://doi.org/10.1016/j.conbuildmat.2018.08.166

25. Ibrahim, M., Rahman, M. K., Johari, M. A. M., \& Maslehuddin, M. (2018c). Effect of Incorporating Nano-silica on the Strength of Natural Pozzolan-Based Alkali-Activated Concrete. In International Congress on Polymers in Concrete (pp. 703-709). Springer, Cham. https://doi.org/10.1007/978-3-319-781754_90

26. Janaki, A. M., Shafabakhsh, G., \& Hassani, A. (2021). Laboratory Evaluation of Alkali-Activated Slag Concrete Pavement Containing Silica fume and Carbon Nanotubes. Engineering Journal, 25(5), 21-31. https://doi.org/10.4186/ej.2021.25.5.21

27. Jindal, B. B., Parveen, Singhal, D., \& Goyal, A. (2017). Predicting relationship between mechanical properties of low calcium fly ash-based geopolymer concrete. Transactions of the Indian Ceramic Society, 76(4), 258-265. https://doi.org/10.1080/0371750X.2017.1412837

28. Kotop, M. A., El-Feky, M. S., Alharbi, Y. R., Abadel, A. A., \& Binyahya, A. S. (2021). Engineering properties of geopolymer concrete incorporating hybrid nanomaterials. Ain Shams Engineering Journal. https://doi.org/10.1016/j.asej.2021.04.022

29. Lazaro, A., Yu, Q. L., \& Brouwers, H. J. H. (2016). Nanotechnologies for sustainable construction. In Sustainability of construction materials (pp. 55-78). Woodhead Publishing.

30. Mahasenan, N., Smith, S., \& Humphreys, K. (2003, January). The cement industry and global climate change: current and potential future cement industry CO2 emissions. In Greenhouse Gas Control Technologies-6th International Conference (pp. 995-1000). Pergamon.

31. Mahboubi, B., Guo, Z., \& Wu, H. (2019). Evaluation of durability behavior of geopolymer concrete containing Nano-silica and Nano-clay additives in acidic media. Journal of civil Engineering and Materials Application, 3(3), 163-171. https://doi.org/10.22034/JCEMA.2019.95839

32. Malerba, D., Esposito, F., Ceci, M., \& Appice, A. (2004). Top-down induction of model trees with regression and splitting nodes. IEEE Transactions on Pattern Analysis and Machine Intelligence, 26(5), 612-625. https://doi.org/10.1109/TPAMI.2004.1273937

33. Mohammed, A. A., Ahmed, H. U., \& Mosavi, A. (2021). Survey of Mechanical Properties of Geopolymer Concrete: A Comprehensive Review and Data Analysis. Materials, 14(16), 4690. https://doi.org/10.3390/ma14164690

34. Mohammed, A. S. (2018). Vipulanandan models to predict the electrical resistivity, rheological properties and compressive stress-strain behavior of oil well cement modified with silica nanoparticles. Egyptian journal of petroleum, 27(4), 1265-1273. https://doi.org/10.1016/j.ejpe.2018.07.001

35. Mohammed, A., Mahmood, W., \& Ghafor, K. (2020). TGA, rheological properties with maximum shear stress and compressive strength of cement-based grout modified with polycarboxylate polymers. Construction and Building Materials, 235, 117534. https://doi.org/10.1016/j.conbuildmat.2019.117534

36. Mohammed, A., Rafiq, S., Sihag, P., Kurda, R., \& Mahmood, W. (2021). Soft computing techniques: systematic multiscale models to predict the compressive strength of HVFA concrete based on mix proportions and curing times. Journal of Building Engineering, 33, 101851. https://doi.org/10.1016/j.jobe.2020.101851

37. Mustakim, S. M., Das, S. K., Mishra, J., Aftab, A., Alomayri, T. S., Assaedi, H. S., \& Kaze, C. R. (2020). Improvement in fresh, mechanical and microstructural properties of fly ash-blast furnace slag based geopolymer concrete by addition of nano and micro silica. Silicon, 1-14. https://doi.org/10.1007/s12633020-00593-0

38. Naskar, S., \& Chakraborty, A. K. (2016). Effect of nano materials in geopolymer concrete. Perspectives in science, 8, 273275. https://doi.org/10.1016/j.pisc.2016.04.049

39. Nuaklong, P., Jongvivatsakul, P., Pothisiri, T., Sata, V., \& Chindaprasirt, P. (2020). Influence of rice husk ash on mechanical properties and fire resistance of recycled aggregate high-calcium fly ash geopolymer concrete. Journal of Cleaner Production, 252, 119797. https://doi.org/10.1016/j.jclepro.2019.119797

40. Nuaklong, P., Sata, V., Wongsa, A., Srinavin, K., \& Chindaprasirt, P. (2018). Recycled aggregate high calcium fly ash geopolymer concrete with inclusion of OPC and nano-SiO2. Construction and Building Materials, 174, 244-252. https://doi.org/10.1016/j.conbuildmat.2018.04.123

41. Omer, S. A., Demirboga, R., \& Khushefati, W. H. (2015). Relationship between compressive strength and UPV of GGBFS based geopolymer mortars exposed to elevated temperatures. Construction and Building Materials, 94, 189-195. https://doi.org/10.1016/j.conbuildmat.2015.07.006

42. Oyebisi, S., Ede, A., Olutoge, F., \& Omole, D. (2020). Geopolymer concrete incorporating agro-industrial wastes: Effects on mechanical properties, microstructural behaviour and mineralogical phases. Construction and Building Materials, 256, 119390. https://doi.org/10.1016/j.conbuildmat.2020.119390

43. Patel, Y., Patel, I. N., \& Shah, M. J. (2015). Experimental investigation on compressive strength and durability properties of geopolymer concrete incorporating with nano silica. International journal of civil engineering and technology, 6(5), 135-143. 
44. Provis, J. L., Palomo, A., \& Shi, C. (2015). Advances in understanding alkali-activated materials. Cement and Concrete Research, 78, 110125. https://doi.org/10.1016/j.cemconres.2015.04.013

45. Quinlan Ross J., 1992. Learning with continuous classes. In: 5th Australian Joint Conference on Artificial Intelligence, Singapore, pp. 343-348.

46. Rabiaa, E., Mohamed, R. A. S., Sofi, W. H., \& Tawfik, T. A. (2020). Developing Geopolymer Concrete Properties by Using Nanomaterials and Steel Fibers. Advances in Materials Science and Engineering, 2020. https://doi.org/10.1155/2020/5186091

47. Ravitheja, A., \& Kumar, N. K. (2019). A study on the effect of nano clay and GGBS on the strength properties of fly ash based geopolymers. Materials Today: Proceedings, 19, 273-276. https://doi.org/10.1016/j.matpr.2019.06.761

48. Roco, M. C., Williams, R. S., \& Alivisatos, P. (Eds.). (2000). Nanotechnology research directions: IWGN workshop report: vision for nanotechnology in the next decade. Springer Science \& Business Media.

49. Saini, G., \& Vattipalli, U. (2020). Assessing properties of alkali activated GGBS based self-compacting geopolymer concrete using nano-silica. Case Studies in Construction Materials, 12, e00352. https://doi.org/10.1016/j.cscm.2020.e00352

50. Sastry, K. G. K., Sahitya, P., \& Ravitheja, A. (2021). Influence of nano TiO2 on strength and durability properties of geopolymer concrete. Materials Today: Proceedings, 45, 1017-1025. https://doi.org/10.1016/j.matpr.2020.03.139

51. Shahmansouri, A. A., Bengar, H. A., \& Ghanbari, S. (2020a). Compressive strength prediction of eco-efficient GGBS-based geopolymer concrete using GEP method. Journal of Building Engineering, 101326, https://doi.org/10.1016/j.jobe.2020.101326

52. Shahmansouri, A. A., Yazdani, M., Ghanbari, S., Bengar, H. A., Jafari, A., \& Ghatte, H. F. (2020b). Artificial neural network model to predict the compressive strength of eco-friendly geopolymer concrete incorporating silica fume and natural zeolite. Journal of Cleaner Production, 279, 123697, https://doi.org/10.1016/j.jclepro.2020.123697

53. Shahrajabian, F., \& Behfarnia, K. (2018). The effects of nano particles on freeze and thaw resistance of alkali-activated slag concrete. Construction and Building Materials, 176, 172-178. https://doi.org/10.1016/j.conbuildmat.2018.05.033

54. Shaikh, F. U. A. (2016). Mechanical and durability properties of fly ash geopolymer concrete containing recycled coarse aggregates. International Journal of Sustainable Built Environment, 5(2), 277-287. https://doi.org/10.1016/j.ijsbe.2016.05.009

55. Sihag, P., Jain, P., \& Kumar, M. (2018). Modelling of impact of water quality on recharging rate of storm water filter system using various kernel function based regression. Modeling earth systems and environment, 4(1), 61-68. https://doi.org/10.1007/s40808-017-0410-0

56. Their, J. M., \& Özakça, M. (2018). Developing geopolymer concrete by using cold-bonded fly ash aggregate, nano-silica, and steel fiber. Construction and Building Materials, 180, 12-22. https://doi.org/10.1016/j.conbuildmat.2018.05.274

57. Velay-Lizancos, M., Perez-Ordoñez, J. L., Martinez-Lage, I., \& Vazquez-Burgo, P. (2017). Analytical and genetic programming model of compressive strength of eco concretes by NDT according to curing temperature. Construction and Building Materials, 144, 195-

206. https://doi.org/10.1016/j.conbuildmat.2017.03.123

58. Vyas, S., Mohammad, S., Pal, S., \& Singh, N. (2020). Strength and durability performance of fly ash based geopolymer concrete using nano silica. International Journal of Engineering Science Technologies, 4(2), 1-12. https://doi.org/10.29121/ijoest.v4.i2.2020.73

59. Weil, M., Dombrowski, K., \& Buchwald, A. (2009). Life-cycle analysis of geopolymer. In Geopolymers (pp. 194-210). Woodhead Publishing. https://doi.org/10.1533/9781845696382.2.194

60. Wiesner, M. R., \& Bottero, J. Y. (2017). Environmental nanotechnology: applications and impacts of nanomaterials. McGraw-Hill Education. https://www.accessengineeringlibrary.com/content/book/9780071828444

61. Yildirim, G., Sahmaran, M., \& Ahmed, H. U. (2015). Influence of hydrated lime addition on the self-healing capability of high-volume fly ash incorporated cementitious composites. Journal of Materials in Civil Engineering, 27(6), 04014187. https://doi.org/10.1061/(ASCE)MT.1943-5533.0001145

\section{Tables}

Table 1

Properties and dosages of NPs reported in the literature to modify geopolymer concrete 


\begin{tabular}{|c|c|c|c|c|}
\hline References & Binder & $\begin{array}{l}\text { Type } \\
\text { of } \\
\text { NPs }\end{array}$ & NPs\% & Properties of NPs \\
\hline $\begin{array}{l}\text { Mustakim et al., } \\
2020\end{array}$ & F- GGBFS & nS & $\begin{array}{l}0,0.5,1 \\
1.5,2 \& \\
2.5 \%\end{array}$ & NA \\
\hline Çevik et al., 2018 & $\mathrm{~F}$ & $\mathrm{nS}$ & $0.0 \& 3 \%$ & $99.8 \% \mathrm{SiO}_{2}$ \\
\hline Sastry et al., 2021 & $\mathrm{~F}$ & $\mathrm{nT}$ & $\begin{array}{l}0,1,2,3,4 \\
\& 5 \%\end{array}$ & $59.93 \%$ titanium and $40.55 \%$ oxygen, Grain size $(20-10 \mu \mathrm{m})$ \\
\hline \multirow[t]{2}{*}{ Rabiaa et al., 2020} & GGBFS & nS & $\begin{array}{l}0,2,4,6, \& \\
8 \%\end{array}$ & Particle size $=14 \mathrm{~nm}$, Surface area $\left(\mathrm{m}^{2} / \mathrm{g}\right)=200,99.65 \% \mathrm{SiO}_{2}$ \\
\hline & & $\mathrm{nM}$ & $\begin{array}{l}0,2,4,6, \& \\
8 \%\end{array}$ & Particle size $=88.7 \mathrm{~nm}$, Surface area $\left(\mathrm{m}^{2} / \mathrm{g}\right)=140.792,45.5 \% \mathrm{SiO} 2,37 \% \mathrm{Al}_{2} \mathrm{O}_{3}$ \\
\hline Adak et al., 2017 & $\mathrm{~F}$ & nS & $0.0 \& 6 \%$ & $\begin{array}{l}\text { Particle size }=4-16 \mathrm{~nm} \text {, Solid content }(\% \mathrm{Wt} .)=31 \text {, density }\left(\mathrm{g} / \mathrm{cm}^{3}\right)=2.37 \text {, Viscosity }(\mathrm{Pa} . \mathrm{S})=8.5 \text {, } \\
\mathrm{pH}=9.0-9.6\end{array}$ \\
\hline $\begin{array}{l}\text { Behfarnia and } \\
\text { Rostami, } 2017\end{array}$ & GGBFS & nS & $\begin{array}{l}0,0.5,1,3 \\
\& 5 \%\end{array}$ & Purity $(\%)=99.8$, Particle size $=20-30 \mathrm{~nm}$, Density $\left(\mathrm{kg} / \mathrm{m}^{3}\right)=200$, Blain $\left(\mathrm{m}^{2} / \mathrm{g}\right)=193$ \\
\hline $\begin{array}{l}\text { Nuaklong et al., } \\
2020\end{array}$ & $\mathrm{~F}+\mathrm{RHA}$ & nS & $\begin{array}{l}0,1,2, \& \\
3 \%\end{array}$ & Purity $(\%)=99.8$, average size $=12 \mathrm{~nm}$, Surface area $\left(\mathrm{m}^{2} / \mathrm{g}\right)=200$ \\
\hline Patel et al., 2015 & $\mathrm{~F}$ & nS & $\begin{array}{l}0,0.5,1, \& \\
1.5 \%\end{array}$ & $\begin{array}{l}\text { Surface area }\left(\mathrm{m}^{2} / \mathrm{g}\right)=200 \pm 25 \text {, average size }=12 \mathrm{~nm}, \text { Purity }(\%)=99.8, \mathrm{PH} \text { in } 4 \% \\
\text { dispersion }=3.4-4.7, \text { Moisture } 2 \text { hours at } 105^{\circ} \mathrm{c}(\text { Wt. } \%)<=1.5\end{array}$ \\
\hline Ibrahim et al, 2018a & NP & nS & $\begin{array}{l}0,1,2.5,5 \\
\& 7.5 \%\end{array}$ & $\begin{array}{l}\text { Solid content }(\%)=50 \text {, Average particle size }(\mathrm{nm})=35 \text {, Bulk density }\left(\mathrm{g} / \mathrm{cm}^{3}\right)=1.4 \text {, Specific } \\
\text { surface area }\left(\mathrm{m}^{2} / \mathrm{g}\right)=80, \mathrm{Na}_{2} \mathrm{O} \text { content }(\%)=0.2 \text {, Viscosity }(\mathrm{cps})=15, \mathrm{pH}=9.5\end{array}$ \\
\hline \multirow[t]{2}{*}{$\begin{array}{l}\text { Mahboubi et al., } \\
2019\end{array}$} & MK & $\mathrm{nS}$ & $\begin{array}{l}0,1,2, \& \\
3 \%\end{array}$ & NA \\
\hline & & $\mathrm{nC}$ & $\begin{array}{l}0,1,2, \& \\
3 \%\end{array}$ & \\
\hline \multirow[t]{3}{*}{$\begin{array}{l}\text { Naskara and } \\
\text { Chakraborty, } 2016\end{array}$} & $\mathrm{~F}$ & nS & $\begin{array}{l}0,0.75,3 \\
\& 6 \%\end{array}$ & NA \\
\hline & & $\mathrm{nT}$ & $\begin{array}{l}0.0 \text { and } \\
1 \%\end{array}$ & \\
\hline & & CNT & $\begin{array}{l}0.0 \text { and } \\
0.02 \%\end{array}$ & \\
\hline $\begin{array}{l}\text { Nuaklong et al., } \\
2018\end{array}$ & $\mathrm{~F}+\mathrm{OPC}$ & nS & $\begin{array}{l}0,1,2, \& \\
3 \%\end{array}$ & average diameter $=40 \mathrm{~nm}$, density $=0.13 \mathrm{~g} / \mathrm{cm}^{3}$, BET specific area $=50 \mathrm{~m}^{2} / \mathrm{g}$, Purity $(\%)=99.8$ \\
\hline $\begin{array}{l}\text { Ravitheja and } \\
\text { Kumar, } 2019\end{array}$ & $\mathrm{~F}+\mathrm{GGBFS}$ & $\mathrm{nC}$ & $\begin{array}{l}0,4,6,8, \& \\
10 \%\end{array}$ & NA \\
\hline Emad et al., 2017 & GGBFS & nS & $0.0 \& 2 \%$ & average particle size $=30 \mathrm{~nm}$, surface area $=45 \mathrm{~m}^{2} / \mathrm{g}, \quad$ Purity $(\%)=99.17$ \\
\hline Vyas et al., 2020 & $\mathrm{~F}$ & nS & $\begin{array}{l}0,2,4,6, \& \\
8 \%\end{array}$ & average particle size $=10 \mathrm{~nm}$ \\
\hline Etemadi et al., 2020 & GGBFS & nS & $\begin{array}{l}0,1,2, \& \\
3 \%\end{array}$ & NA \\
\hline $\begin{array}{l}\text { Angelin Lincy and } \\
\text { Velkennedy, } 2020\end{array}$ & GGBFS & ns & $\begin{array}{l}0,0.5, \& \\
1 \%\end{array}$ & Purity $(\%)=99.9$, Surface area $\left(\mathrm{m}^{2} / \mathrm{g}\right)=201$, Specific gravity $=2.34$ \\
\hline $\begin{array}{l}\text { Saini and Vattipalli, } \\
2020\end{array}$ & GGBFS & nS & $0.0 \& 2 \%$ & $\begin{array}{l}\text { Purity }(\%)=99.88, \text { Particle Size }=17 \mathrm{~nm} \text {, Specific Gravity }=2.3 \text {, Specific Surface Area } \\
\left(\mathrm{m}^{2} / \mathrm{g}\right)=202, \mathrm{PH} \text { Value }=4.12 \text {, Tamped Density }(\mathrm{g} / \mathrm{L})=44\end{array}$ \\
\hline \multirow[t]{2}{*}{ Kotop et al., 2021} & $F+G G B F S$ & $\mathrm{nC}$ & $\begin{array}{l}0,2.5,5, \& \\
7 \%\end{array}$ & $\mathrm{SiO}_{2}=61.24, \mathrm{Al} 2 \mathrm{O} 3=20.89$ \\
\hline & & CNT & $\begin{array}{l}0.01 \\
0.02 \%\end{array}$ & Length $=10-100 \mathrm{~mm}$, inner diameter $=1.5-15 \mathrm{~nm}$, outer diameter $=50 \mathrm{~nm}$ \\
\hline Ibrahim et al, 2018b & NP & nS & $\begin{array}{l}0,1,2.5,5 \\
\& 7.5 \%\end{array}$ & $\begin{array}{l}\text { Solid content }(\%)=50 \text {, Average particle size }(\mathrm{nm})=35 \text {, Bulk density }\left(\mathrm{g} / \mathrm{cm}^{3}\right)=1.4 \text {, Specific } \\
\text { surface area }\left(\mathrm{m}^{2} / \mathrm{g}\right)=80, \mathrm{Na}_{2} \mathrm{O} \text { content }(\%)=0.2 \text {, Viscosity }(\mathrm{cps})=15, \mathrm{pH}=9.5\end{array}$ \\
\hline \multirow[t]{3}{*}{$\begin{array}{l}\text { Shahrajabian and } \\
\text { Behfarnia, } 2018\end{array}$} & GGBFS & $\mathrm{nA}$ & $\begin{array}{l}0,1,2, \& 3 \\
\%\end{array}$ & Particle size $(\mathrm{nm})=20$, Blaine $(\mathrm{m} 2 / \mathrm{gr})=100$, Purity $(\%)=99.7$ \\
\hline & & $\mathrm{nC}$ & $\begin{array}{l}0,1,2, \& 3 \\
\%\end{array}$ & Particle size $(\mathrm{nm})=1-2$, Blaine $(\mathrm{m} 2 / \mathrm{gr})=220-270$, Density $(\mathrm{g} / \mathrm{cm} 3)=0.5-0.7$ \\
\hline & & nS & $0,1,2, \& 3$ & \\
\hline
\end{tabular}


Their and Özakça, F- FGBFS nS $0.0 \& 2 \%$

2018

specific surface area $=170-230 \mathrm{~m}^{2} / \mathrm{g}$, Specific gravity $=2.2$, Purity $(\%)=99.8$

Ibrahim et al., 2018c

NP

nS $\quad 0,1,2.5,5$,

Solid content $(\%)=50$, Average particle size $(\mathrm{nm})=35$, Bulk density $\left(\mathrm{g} / \mathrm{cm}^{3}\right)=1.4$, Specific surface area $\left(\mathrm{m}^{2} / \mathrm{g}\right)=80, \mathrm{Na}_{2} \mathrm{O}$ content $(\%)=0.2$, Viscosity $(\mathrm{cps})=15, \mathrm{pH}=9.5$

Janaki et al., 2021

GGBFS+SF CNT

$0,2,5$, and

CNTs have diameter of 20 to $120 \mathrm{~nm}$ and are several micrometers in length. $10 \%$

NPs=nano-particles; $F=$ fly ash; GGBFS= ground granulated blast furance slag; $M K=$ metakaolin; $S F=$ silica-fume; $R H A=$ rice husk ash; $N P=n a t u r a l$

pozzolan; OPC=ordinary Portland cement; nS= nano-SiO2; nT=nano-TiO2; nM= nano-metakaolin; nC=nano-clay; $\mathrm{CNT}=$ carbon nanotube; $\mathrm{nA}=$ nano-Al2O3

\section{Table 2}

Summary of the constitutes of geopolymer concrete mixes reported in the literature 


\begin{tabular}{|c|c|c|c|c|c|c|c|c|c|c|c|c|}
\hline Ref. & $l / b$ & $\begin{array}{l}\mathrm{b} \\
\left(\mathrm{kg} / \mathrm{m}^{3}\right)\end{array}$ & $\begin{array}{l}\mathrm{FA} \\
(\mathrm{kg} / \mathrm{m} 3)\end{array}$ & $\begin{array}{l}\mathrm{CA} \\
(\mathrm{kg} / \mathrm{m} 3)\end{array}$ & $\begin{array}{l}\mathrm{SH} \\
(\mathrm{kg} / \mathrm{m} 3)\end{array}$ & $\begin{array}{l}\mathrm{SS} \\
(\mathrm{kg} / \mathrm{m} 3)\end{array}$ & M & SS/SH & $\begin{array}{l}\text { NS } \\
\left(\mathrm{kg} / \mathrm{m}^{3}\right)\end{array}$ & $\begin{array}{l}\mathrm{T} \\
\left({ }^{\circ} \mathrm{C}\right)\end{array}$ & $\begin{array}{l}\text { A } \\
\text { (days) }\end{array}$ & $\begin{array}{l}\mathrm{CS} \\
(\mathrm{MPa})\end{array}$ \\
\hline Mustakim et al., 2020 & 0.45 & $486-490$ & 490 & 1470 & 73 & 154 & 12 & 2 & $0-3.675$ & 31.5 & 3_28 & $\begin{array}{l}8.95- \\
62.8\end{array}$ \\
\hline Çevik et al., 2018 & 0.45 & 500 & 575 & 1150 & 64.3 & 160.7 & 14 & 2.5 & $0-15$ & 70 & 30 & $\begin{array}{l}51.63- \\
42.71\end{array}$ \\
\hline Rabiaa et al., 2020 & 0.45 & $500-460$ & 790 & 907 & 62.5 & 187.5 & 12 & 2.33 & $0-40$ & 28 & 7_28 & $29-48$ \\
\hline Adak et al., 2017 & 0.4 & 440 & 723 & 1085 & 64 & 112 & 12 & 1.75 & $0-26.4$ & $\begin{array}{l}28- \\
60\end{array}$ & 3_28 & $\begin{array}{l}21.7- \\
46.43\end{array}$ \\
\hline $\begin{array}{l}\text { Behfarnia and Rostami, } \\
2017\end{array}$ & 0.45 & $393-414$ & $692-684$ & $\begin{array}{l}1240- \\
1233\end{array}$ & $\begin{array}{l}46.6- \\
44.2\end{array}$ & $\begin{array}{l}139.7- \\
132.6\end{array}$ & 4 & 3 & $0-20.7$ & 23 & $28-60$ & $\begin{array}{l}52- \\
76.5\end{array}$ \\
\hline Nuaklong et al., 2020 & 0.6 & 450 & 500 & $\begin{array}{l}970- \\
1150\end{array}$ & 135 & 135 & 10 & 1 & $0-13.5$ & 25 & 7_90 & $\begin{array}{l}18.6- \\
47.3\end{array}$ \\
\hline Patel et al., 2015 & 0.45 & 380.689 & 554.4 & 1295 & 48.945 & 122.364 & 8_16 & 2.5 & $0-5.71$ & 60 & 28 & 38.1 \\
\hline Ibrahim et al, 2018a & 0.52 & $370-400$ & 650 & 1206 & 60 & 150 & 14 & 2.5 & $0-30$ & 60 & 1_28 & $4.7-45$ \\
\hline Mahboubi et al., 2019 & 0.6 & 300 & 800 & 1200 & 85 & 95 & 12 & 1.1 & $0-9$ & 25 & 7_28 & $\begin{array}{l}18.9- \\
45.9\end{array}$ \\
\hline $\begin{array}{l}\text { Naskara and Chakraborty, } \\
2016\end{array}$ & 0.5 & $339-350$ & 720 & 1305 & $43.5-45$ & $\begin{array}{l}108.9- \\
112.5\end{array}$ & 16 & 2.5 & $0-21$ & 60 & 7_28 & $\begin{array}{l}3.2- \\
24.4\end{array}$ \\
\hline Nuaklong et al., 2018 & 0.6 & 450 & 500 & $\begin{array}{l}1036- \\
1150\end{array}$ & 108 & 162 & 12 & 1.5 & $0-9$ & 60 & 28 & $\begin{array}{l}31.6- \\
42.6\end{array}$ \\
\hline Vyas et al., 2020 & 0.45 & 497 & 560 & 1120 & 159.75 & 63.9 & 12 & 0.4 & $0-49.7$ & 60 & 28 & $24-35$ \\
\hline Etemadi et al., 2020 & 0.5 & 450 & 750 & 1000 & 75 & 150 & 12 & 2 & $0-13.5$ & 25 & 7_28 & $\begin{array}{l}21.9- \\
50.4\end{array}$ \\
\hline $\begin{array}{l}\text { Lincy and Velkennedy, } \\
2020\end{array}$ & 0.4 & 394.29 & 554.4 & 1293.6 & 45.06 & 112.64 & 12 & 2.5 & $0-3.94$ & 24 & 28 & $\begin{array}{l}44.3- \\
48.6\end{array}$ \\
\hline Saini and Vattipalli, 2020 & 0.45 & $450-500$ & 825 & 825 & $\begin{array}{l}18.17- \\
28.57\end{array}$ & $\begin{array}{l}144.65- \\
160.75\end{array}$ & 10_16 & 2.5 & $0-10$ & 60 & 7_90 & $\begin{array}{l}41.1- \\
81.3\end{array}$ \\
\hline Ibrahim et al, 2018b & 0.52 & $370-400$ & $620-650$ & $\begin{array}{l}1152- \\
1206\end{array}$ & 60 & 150 & 14 & 2.5 & $0-60$ & 24 & $3-180$ & $\begin{array}{l}4.3- \\
61.2\end{array}$ \\
\hline $\begin{array}{l}\text { Shahrajabian and } \\
\text { Behfarnia, } 2018\end{array}$ & 0.45 & 362.8 & 990 & 810 & 122.4 & 40.8 & 4 & 0.33 & $0-10.88$ & 25 & $7-120$ & $\begin{array}{l}35.5- \\
61.8\end{array}$ \\
\hline Their and Özakça, 2018 & 0.45 & $\begin{array}{l}405.8- \\
413.8\end{array}$ & 888 & 945 & 53.2 & 133 & 12 & 2.5 & $0-8.3$ & 29 & $28-90$ & $\begin{array}{l}37.1- \\
52.3\end{array}$ \\
\hline Ibrahim et al., $2018 \mathrm{c}$ & 0.52 & $370-400$ & $620-650$ & $\begin{array}{l}1152- \\
1206\end{array}$ & 60 & 150 & 14 & 2.5 & $0-60$ & 60 & $0.5-28$ & $\begin{array}{l}4.9- \\
45.1\end{array}$ \\
\hline Min. & 0.4 & 300 & 490 & 810 & 18.17 & 40.8 & 4 & 0.33 & 0 & 23 & 0.5 & 3.2 \\
\hline Max. & 0.6 & 500 & 990 & 1470 & 159.75 & 187.5 & 16 & 3 & 60 & 70 & 180 & 81.3 \\
\hline St.Div. & 0.1 & 51.9 & 135.3 & 183.3 & 33.9 & 35.6 & 3.3 & 0.8 & 14.6 & 17.4 & 31.8 & 17.5 \\
\hline
\end{tabular}

${ }^{*} \mathrm{l} / \mathrm{b}=$ alkaline solution to binder ratio, $\mathrm{b}=$ binder content $(\mathrm{kg} / \mathrm{m} 3), \mathrm{FA}=\mathrm{fine}$ aggregate content $(\mathrm{kg} / \mathrm{m} 3), \mathrm{CA}=$ coarse aggregate content $\left(\mathrm{kg} / \mathrm{m}^{3}\right), \mathrm{SH}=\mathrm{sodium}$ hydroxide content $\left(\mathrm{kg} / \mathrm{m}^{3}\right)$, SS=sodium silicate content $\left(\mathrm{kg} / \mathrm{m}^{3}\right), \mathrm{M}=$ molarity $(\mathrm{M}), \mathrm{SS} / \mathrm{SH}=$ ratio of sodium silicate to sodium hydroxide, $\mathrm{NS}=$ nano-silica content $\left(\mathrm{kg} / \mathrm{m}^{3}\right), \mathrm{T}=$ curing temperature $\left({ }^{\circ} \mathrm{C}\right), \mathrm{A}=$ age (days), and $\mathrm{CS}=$ tested compressive strength $(\mathrm{MPa})$.

Table 3

The tested ANN architectures 


\begin{tabular}{|llllll|}
\hline No. of Hidden layers & No. of Neurons in left side & No. of Neurons in right side & $\mathbf{R}^{2}$ & MAE (MPa) & RMSE (MPa) \\
\hline 1 & 1 & 0 & 0.9114 & 5.8711 & 7.545 \\
\hline 1 & 2 & 0 & 0.9346 & 5.0137 & 6.1308 \\
\hline 1 & 9 & 0 & 0.9744 & 2.631 & 3.849 \\
\hline 1 & 11 & 0 & 0.9707 & 2.9734 & 4.1676 \\
\hline 2 & 1 & 1 & 0.9085 & 6.144 & 7.8757 \\
\hline 2 & 3 & 3 & 0.9495 & 4.2999 & 5.4882 \\
\hline 2 & 5 & 5 & 0.9707 & 3.1309 & 4.2717 \\
\hline 2 & 7 & 7 & 0.9731 & 2.8988 & 4.0177 \\
\hline 2 & 9 & 9 & 0.9741 & 3.1746 & 4.297 \\
\hline 2 & 11 & 11 & 0.9768 & 2.8848 & 4.0084 \\
\hline 2 & 12 & $\mathbf{1 2}$ & 0.9771 & $\mathbf{2 . 8 3 1 6}$ & $\mathbf{3 . 8 9 2}$ \\
\hline
\end{tabular}

Table 4

M5P-tree model parameters (equation (17)).

\begin{tabular}{lllllll} 
(LM) num: & $\mathbf{1}$ & $\mathbf{2}$ & $\mathbf{3}$ & $\mathbf{4}$ & $\mathbf{5}$ & $\mathbf{6}$ \\
\hline $\boldsymbol{a}$ & -93.696 & +32.7126 & +32.8862 & -2.7578 & -166.0773 & -13.196 \\
$\boldsymbol{b}$ & 274.4776 & 38.4951 & 38.4951 & 38.4951 & 141.2642 & 53.0334 \\
\hline $\boldsymbol{c}$ & +0.0488 & -0.0138 & -0.0138 & +0.0534 & +0.1562 & +0.0806 \\
\hline $\boldsymbol{d}$ & & & & +0.0655 & +0.024 \\
\hline $\boldsymbol{e}$ & +0.0029 & +0.0077 & +0.0077 & +0.0174 & & -0.0269 \\
\hline $\boldsymbol{f}$ & +0.2796 & -0.0513 & -0.0513 & -0.1534 & -0.0386 & -0.0386 \\
\hline $\boldsymbol{g}$ & -0.0501 & +0.0119 & +0.0119 & -0.0114 & -0.0154 & -0.0154 \\
\hline $\boldsymbol{h}$ & -0.5772 & -0.8632 & -0.8632 & -0.8632 & -0.4692 & -0.4692 \\
\hline $\boldsymbol{i}$ & & & & & & \\
\hline $\boldsymbol{j}$ & -0.0307 & -0.0307 & +0.0683 & +0.0516 & -0.0282 & -0.0282 \\
\hline $\boldsymbol{k}$ & & & & & +0.3218 & +0.077 \\
\hline $\boldsymbol{l}$ & +0.1921 & +0.1625 & +0.1575 & +0.2233 & +0.9407 & +0.181
\end{tabular}

Figures 


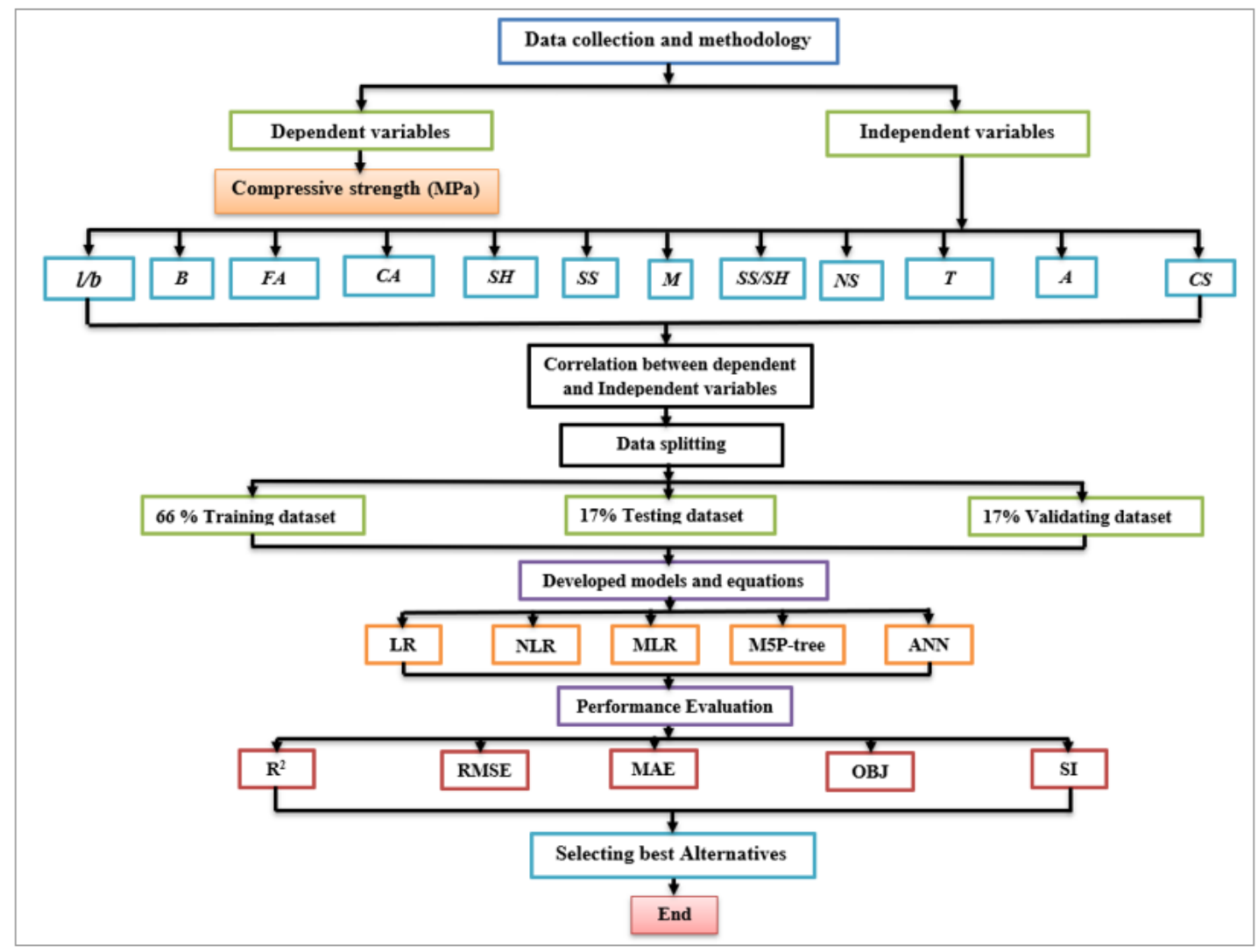

\section{Figure 1}

The flow chart diagram process followed in this study

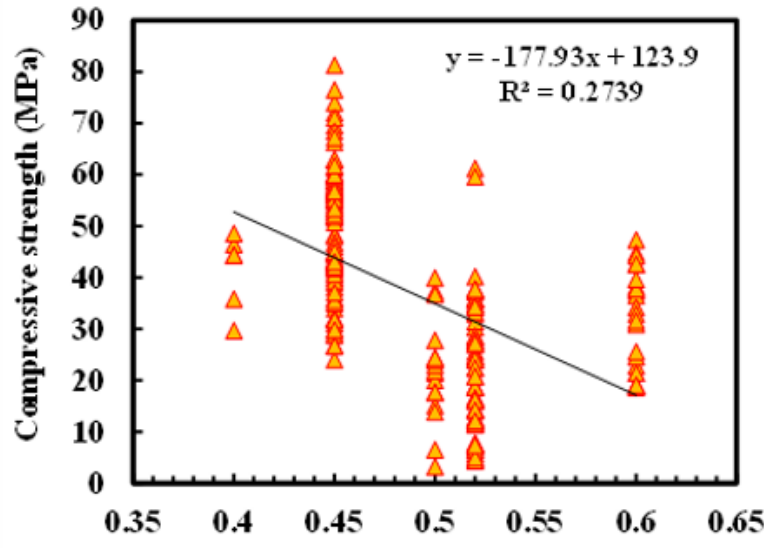

(Alkaline solution/Binder) ratio

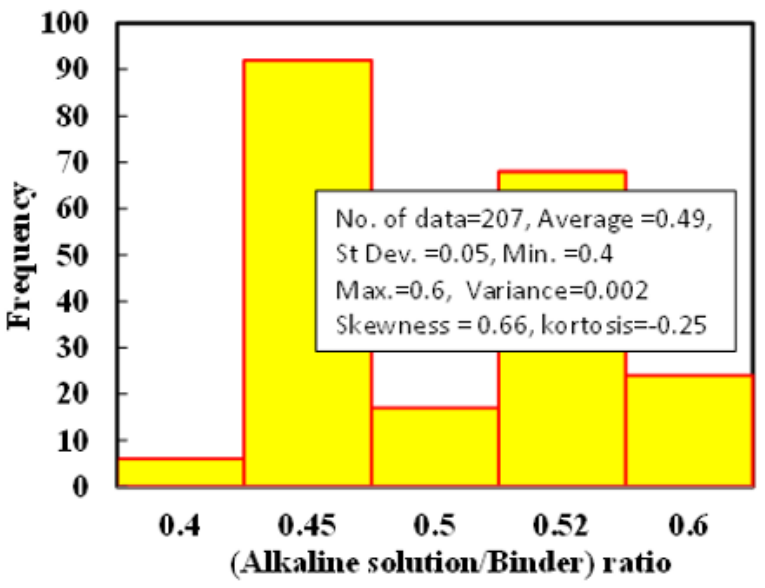

(Alkaline solution/Binder) ratio

Figure 2

Correlations between $\mathrm{CS}$ and $\mathrm{l} / \mathrm{b}$ ratio with histogram of GPC mixtures incorporated $\mathrm{nS}$ 

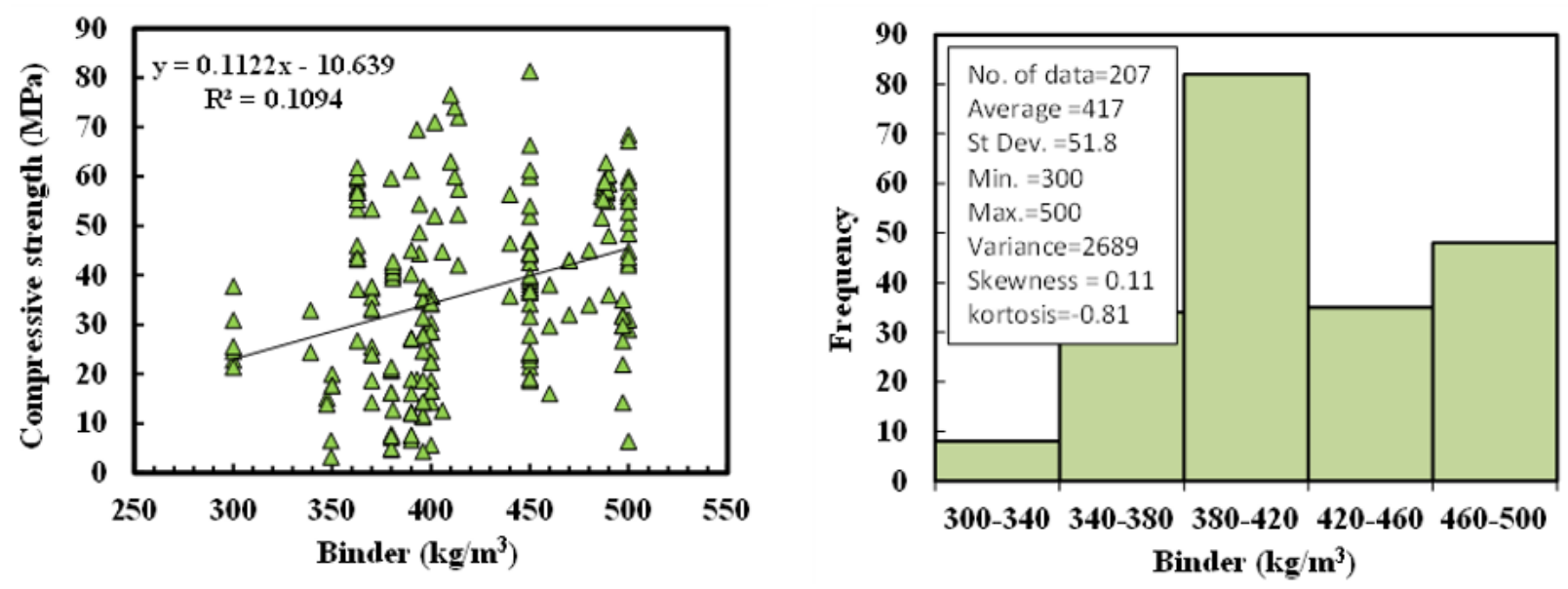

Figure 3

Correlations between CS and binder content with histogram of GPC mixtures incorporated nS
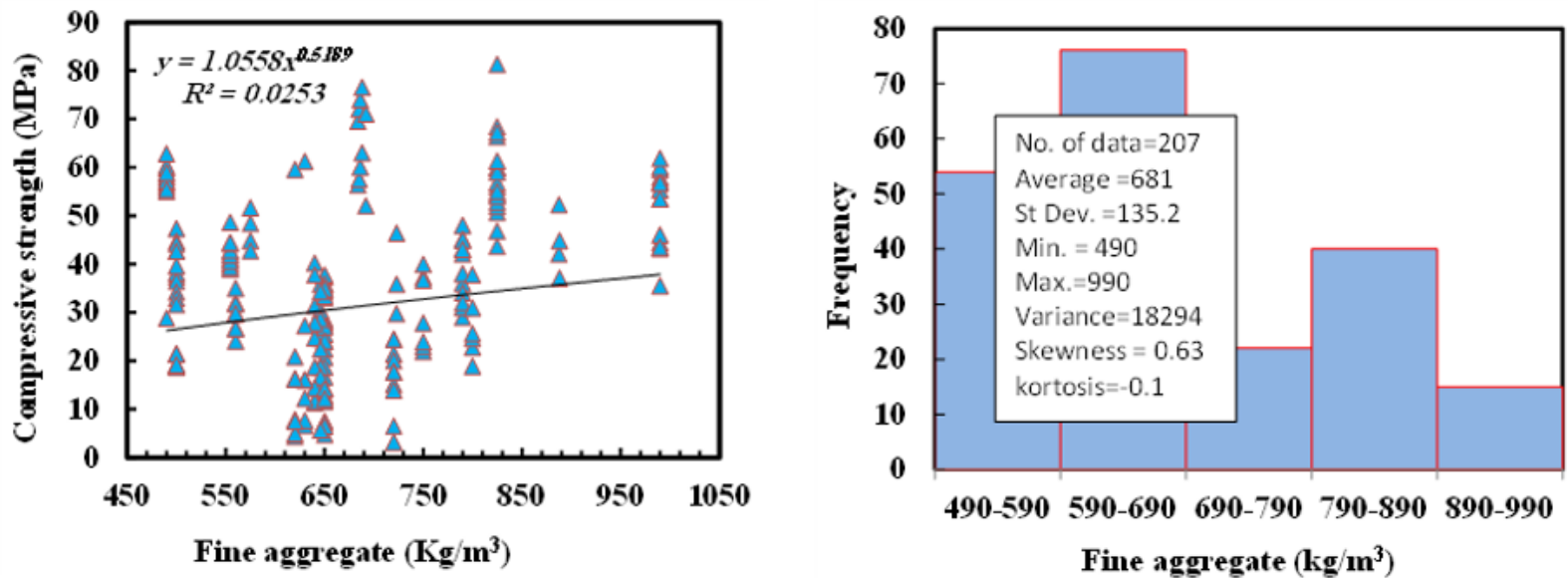

Figure 4

Correlations between CS and FA content with histogram of GPC mixtures incorporated nS
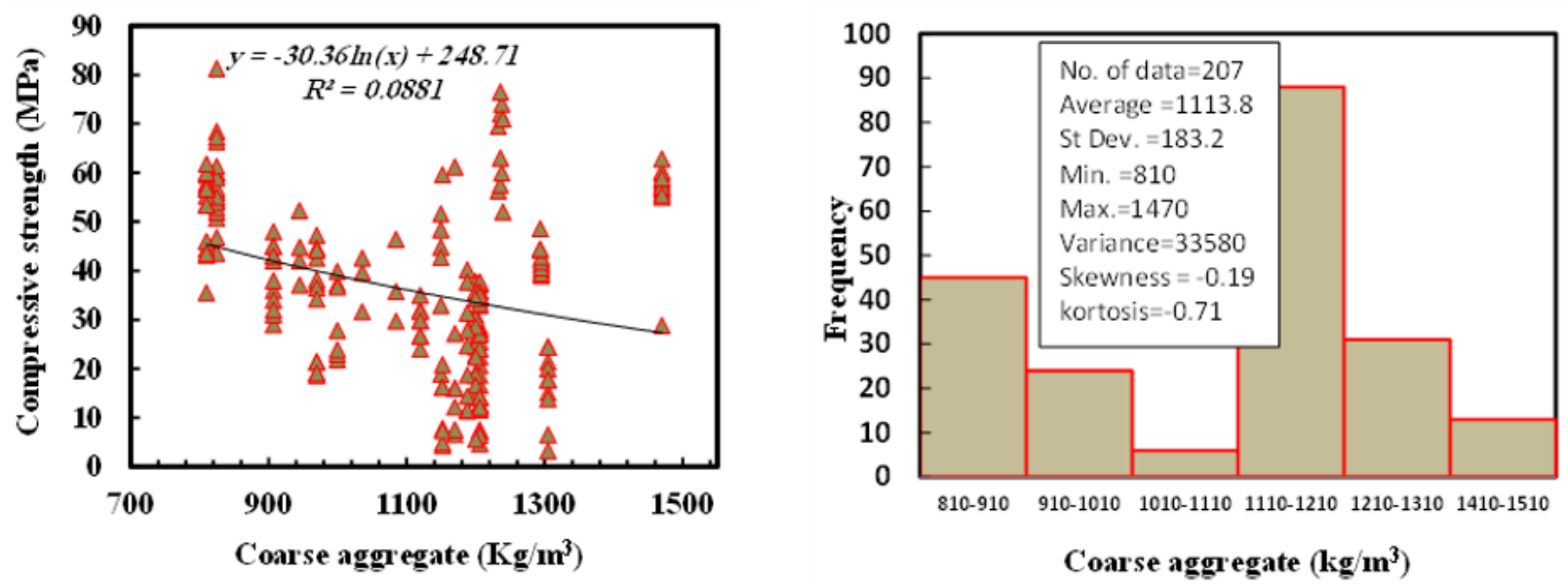

Figure 5 
Figure 6

Correlations between CS and SH content with histogram of GPC mixtures incorporated nS
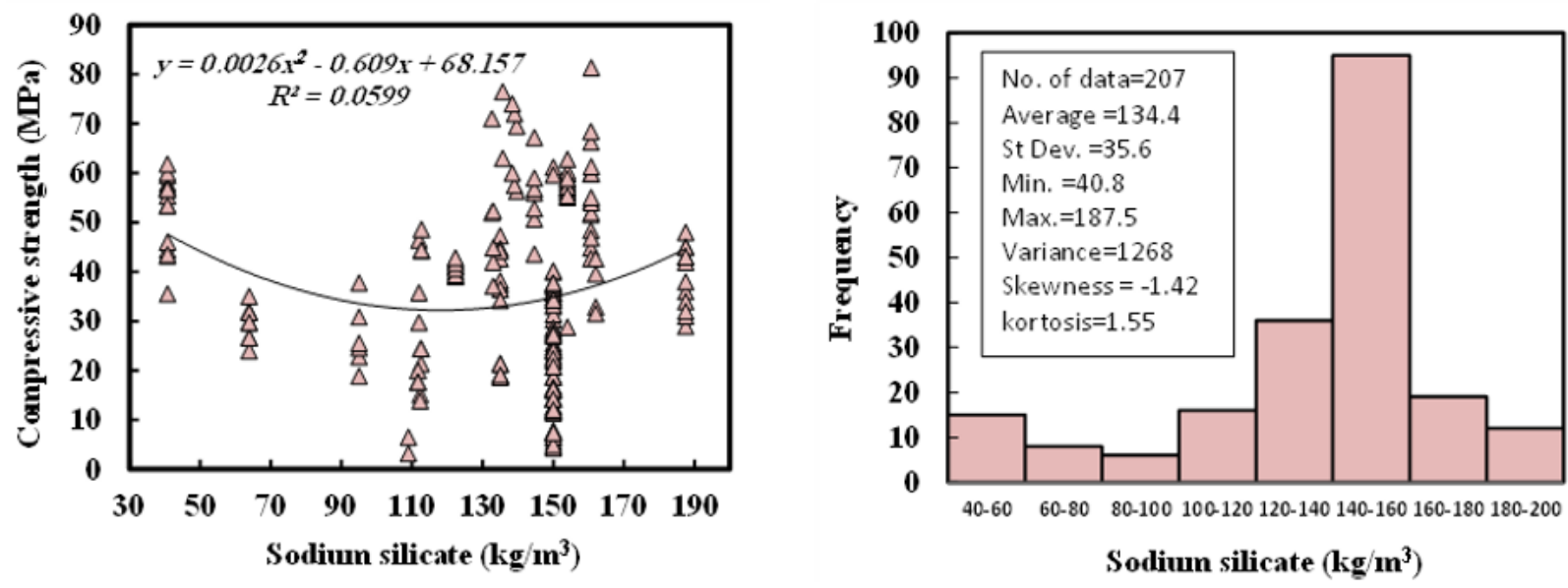

Figure 7

Correlations between CS and SS content with histogram of GPC mixtures incorporated nS

Figure 8

Correlations between $\mathrm{CS}$ and molarity of $\mathrm{SH}$ with histogram of GPC mixtures incorporated nS
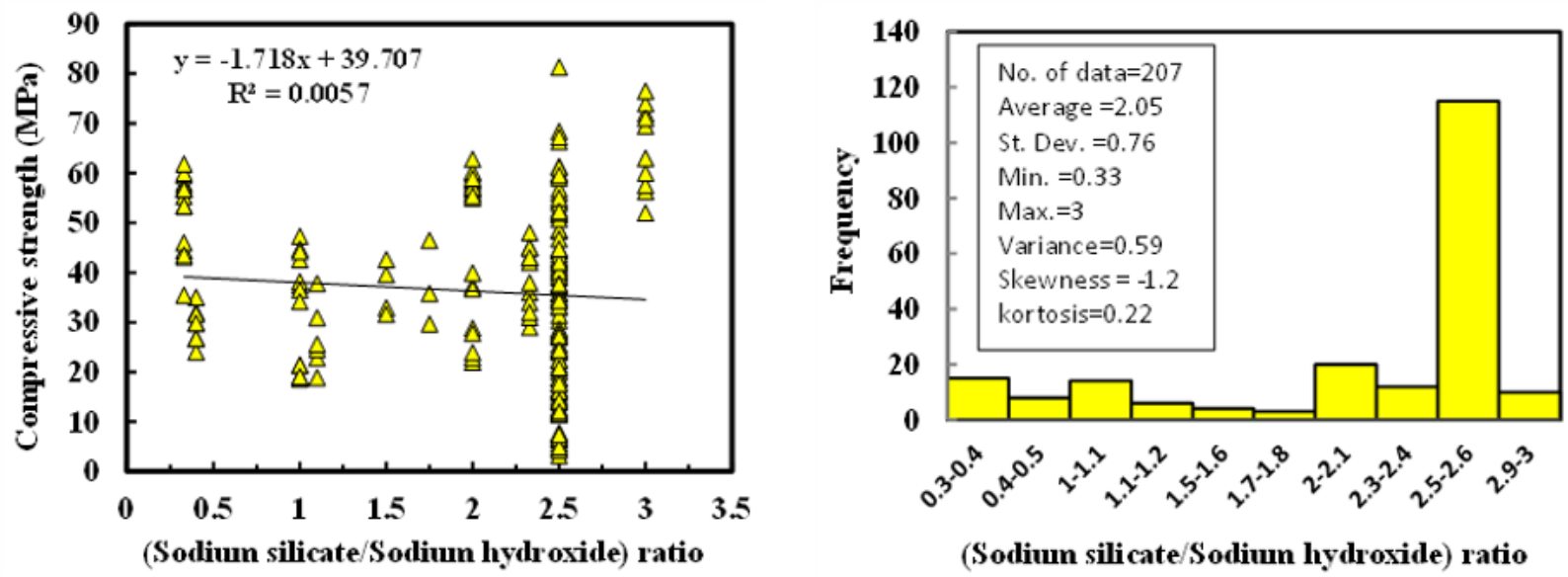

(Sodium silicate/Sodium hydroxide) ratio

Figure 9

Correlations between CS and SS/SH ratio with histogram of GPC mixtures incorporated nS 


\section{Figure 10}

Correlations between CS and nS content with histogram of GPC mixtures incorporated nS
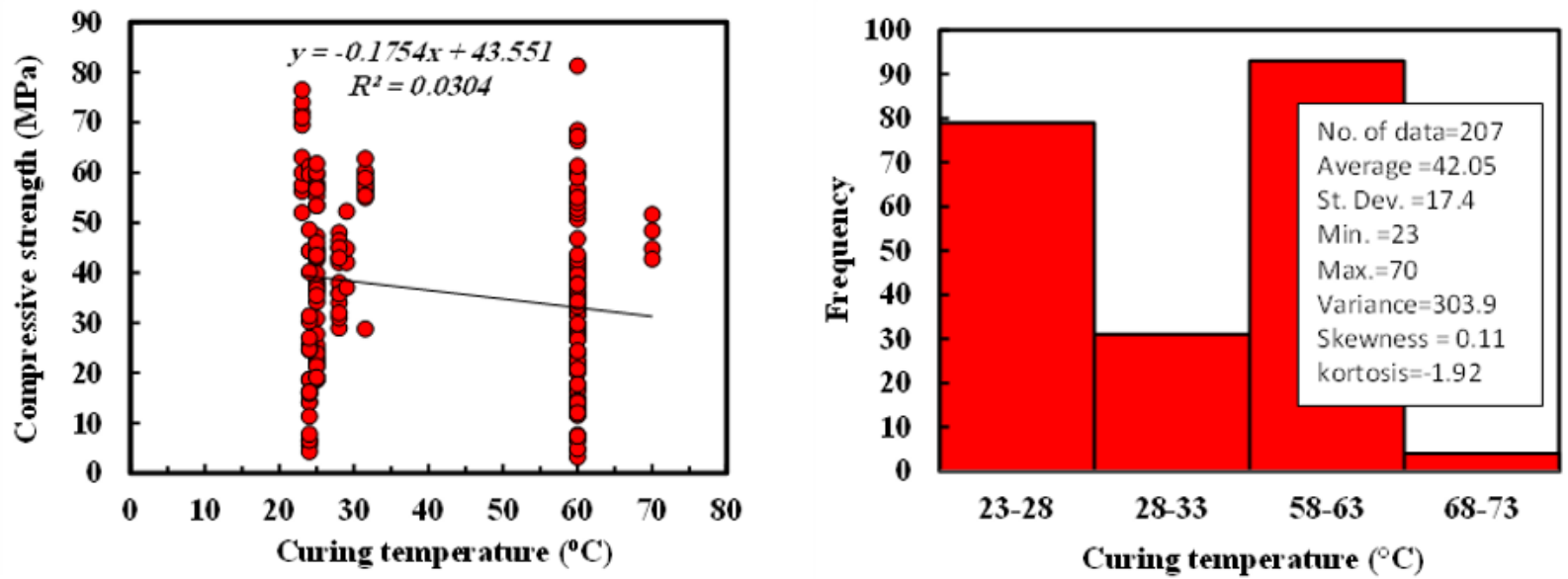

Figure 11

Correlations between CS and T with histogram of GPC mixtures incorporated nS

\section{Figure 12}

Correlations between CS and A with histogram of GPC mixtures incorporated nS

Figure 13

Comparison between tested and predicted CS of GPC mixtures incorporated nS using LR model, (a) training data, (b) testing data, (c) validating data

\section{Figure 14}

Residual error diagram of CS of GPC mixtures incorporated nS using training, testing and validating dataset for LR model

Figure 15

Comparison between tested and predicted CS of GPC mixtures incorporated nS using NLR model, (a) training data, (b) testing data, (c) validating data

\section{Figure 16}

Residual error diagram of CS of GPC mixtures incorporated nS using training, testing and validating dataset for NLR model

Page 20/23 

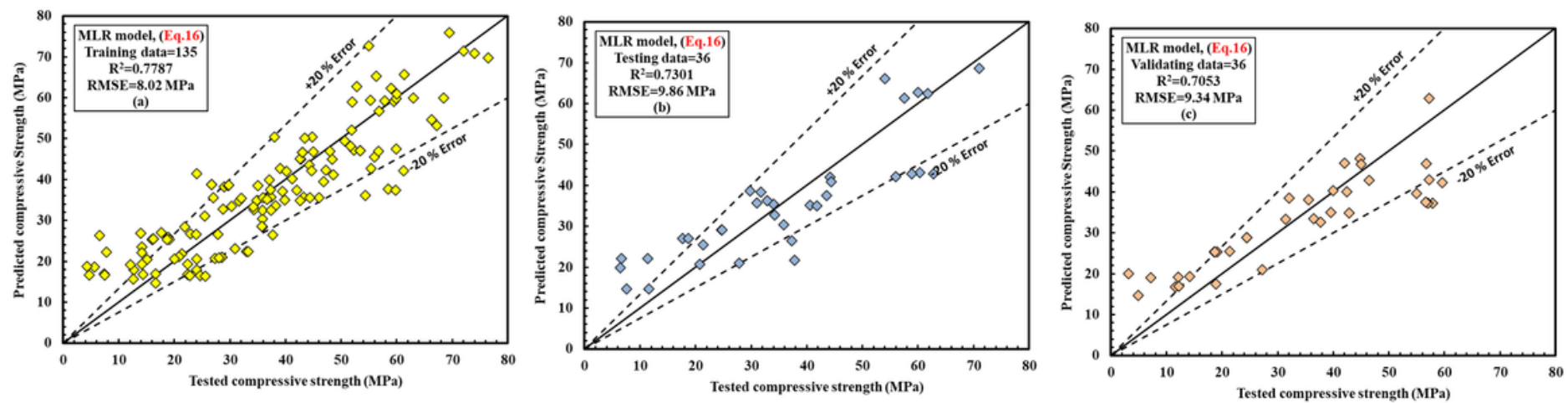

\section{Figure 17}

Comparison between tested and predicted CS of GPC mixtures incorporated nS using MLR model, (a) training data, (b) testing data, (c) validating data

\section{Figure 18}

Residual error diagram of CS of GPC mixtures incorporated nS using training, testing and validating dataset for MLR model

\section{Figure 19}

Optimal network structures of the ANN model

\section{Figure 20}

Comparison between tested and predicted CS of GPC mixtures incorporated nS using ANN model, (a) training data, (b) testing data, (c) validating data

\section{Figure 21}

Residual error diagram of CS of GPC mixtures incorporated nS using training, testing and validating dataset for ANN model 

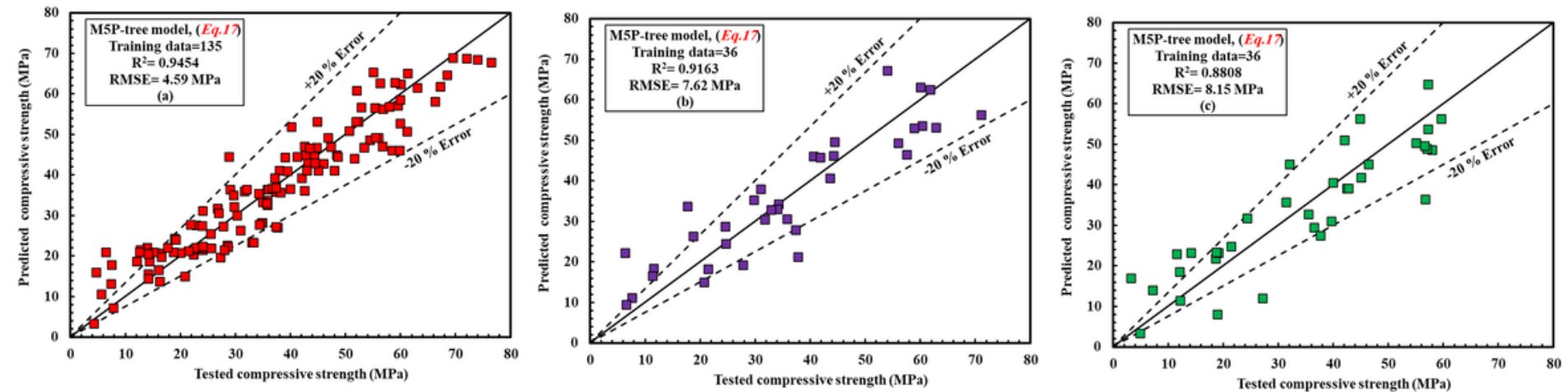

Figure 22

Comparison between tested and predicted CS of GPC mixtures incorporated nS using M5P-tree model, (a) training data, (b) testing data, (c) validating data

Figure 23

M5P-tree Pruned model tree

\section{Figure 24}

Residual error diagram of CS of GPC mixtures incorporated nS using training, testing and validating dataset for M5P model

\section{Figure 25}

The OBJ values of all developed models 


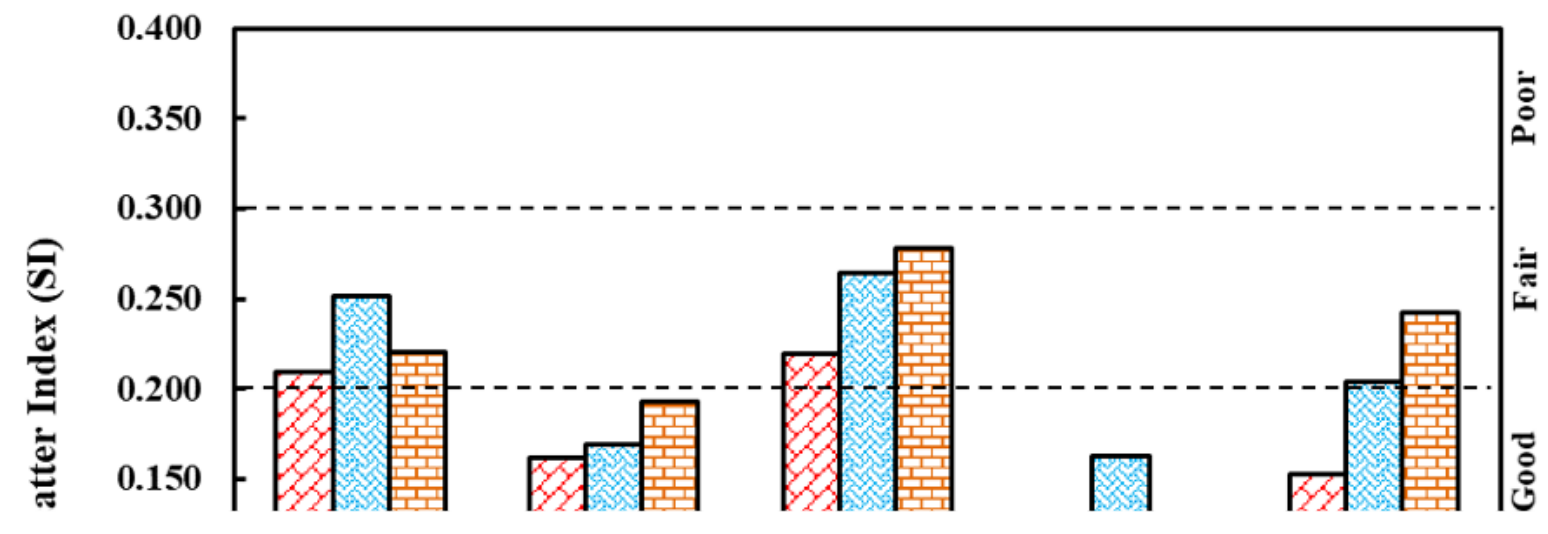

Figure 26

Comparing the SI performance parameter of different developed models

Figure 27

Compression between model predictions of CS of GPC mixtures incorporated nS using testing datasets 